\title{
Multi-Target Approaches in Metabolic Syndrome
}

\author{
Felix F. Lillich ${ }^{1}$, John D. Imig ${ }^{2}$ and Ewgenij Proschak ${ }^{1 *}$ \\ ${ }^{1}$ Institute of Pharmaceutical Chemistry, Goethe-University of Frankfurt, Frankfurt, Germany, ${ }^{2}$ Department of Pharmacology and \\ Toxicology, Medical College of Wisconsin, Milwaukee, WI, United States
}

OPEN ACCESS

Edited by:

Tea Lanisnik Rizner,

University of Ljubljana, Slovenia

Reviewed by:

Marica Cariello,

University of Bari Aldo Moro, Italy

Mong Heng Wang,

Augusta University, United States

Andreas Koeberle,

University of Innsbruck, Austria

${ }^{*}$ Correspondence:

Ewgenij Proschak proschak@pharmchem.

uni-frankfurt.de

Specialty section: This article was submitted to Experimental Pharmacology and Drug Discovery, a section of the journal Frontiers in Pharmacology

Received: 23 April 2020 Accepted: 03 November 2020 Published: 12 March 2021

Citation: Lillich FF, Imig JD and Proschak E (2021) Multi-Target Approaches in Metabolic Syndrome.

Front. Pharmacol. 11:554961. doi: 10.3389/fphar.2020.554961
Metabolic syndrome (MetS) is a highly prevalent disease cluster worldwide. It requires polypharmacological treatment of the single conditions including type II diabetes, hypertension, and dyslipidemia, as well as the associated comorbidities. The complex treatment regimens with various drugs lead to drug-drug interactions and inadequate patient adherence, resulting in poor management of the disease. Multi-target approaches aim at reducing the polypharmacology and improving the efficacy. This review summarizes the medicinal chemistry efforts to develop multi-target ligands for MetS. Different combinations of pharmacological targets in context of in vivo efficacy and future perspective for multi-target drugs in MetS are discussed.

Keywords: metabolic sydrome, polypharmacology, multi-target drug, peroxisome prolifer ators-activated receptor$\gamma$, soluble epoxide hydrolase, farnesoid $\mathbf{X}$ receptor

\section{INTRODUCTION}

Metabolic diseases are becoming increasingly prevalent and have a major impact on public health worldwide (Kahn et al., 2005; Potenza and Mechanick, 2009; Shaw et al., 2010). Major metabolic diseases include metabolic syndrome (MetS), type 2 diabetes, and non-alcoholic fatty liver disease (NAFLD). Insulin resistance is a key component for MetS and metabolic diseases such as type 2 diabetes and NAFLD. MetS patients are diagnosed when they have at least three of the following risk factors: abdominal obesity, hypertriglyceridemia, elevated blood pressure, low high-density lipoprotein (HDL) cholesterol, or glucose intolerance Figure 1 (Grundy et al., 2004; Alberti et al., 2005; Grundy, 2006). Type 2 diabetes afflicts close to 200 million worldwide and type 2 diabetic patients have obesity-related MetS (Grundy et al., 2004; Potenza and Mechanick, 2009; Shaw et al., 2010). Diabetes is already the leading cause of blindness, end-stage liver disease, and end-stage renal disease (Alberti et al., 2005; Kahn et al., 2005). Likewise, NAFLD is the most common chronic liver disease and affects up to one-third of the adult population (Basaranoglu and NeuschwanderTetri, 2006; Sumida and Yoneda, 2018). A large portion of patients with NAFLD display typical features of MetS including abdominal obesity, dyslipidemia, hypertension, insulin resistance, or type 2 diabetes (Chalasani et al., 2012; El-Kader and El-; El-Kader and El-Den Ashmawy, 2015). Developing adequate therapeutic and preventive measures for these multifactorial metabolic diseases has so far been challenging. Indeed, due to the complex pathophysiology, the current therapeutic approaches to treat MetS, type 2 diabetes, and NAFLD need multiple treatments regulating lipid and glucose homeostasis as well as blood pressure control (Grundy et al., 2005; Grundy, 2006; Oseini and Sanyal, 2017; Sumida and Yoneda, 2018).

Apart from the metabolic abnormalities per se, inflammation associated with these metabolic diseases plays a crucial role in increasing cardiovascular events, causing NAFLD progression to hepatocellular cancer, and causing diabetic complications such as nephropathy, neuropathy, and retinopathy (Dandona et al., 2005; Esser et al., 2014). Metabolic diseases induce disruption in many 


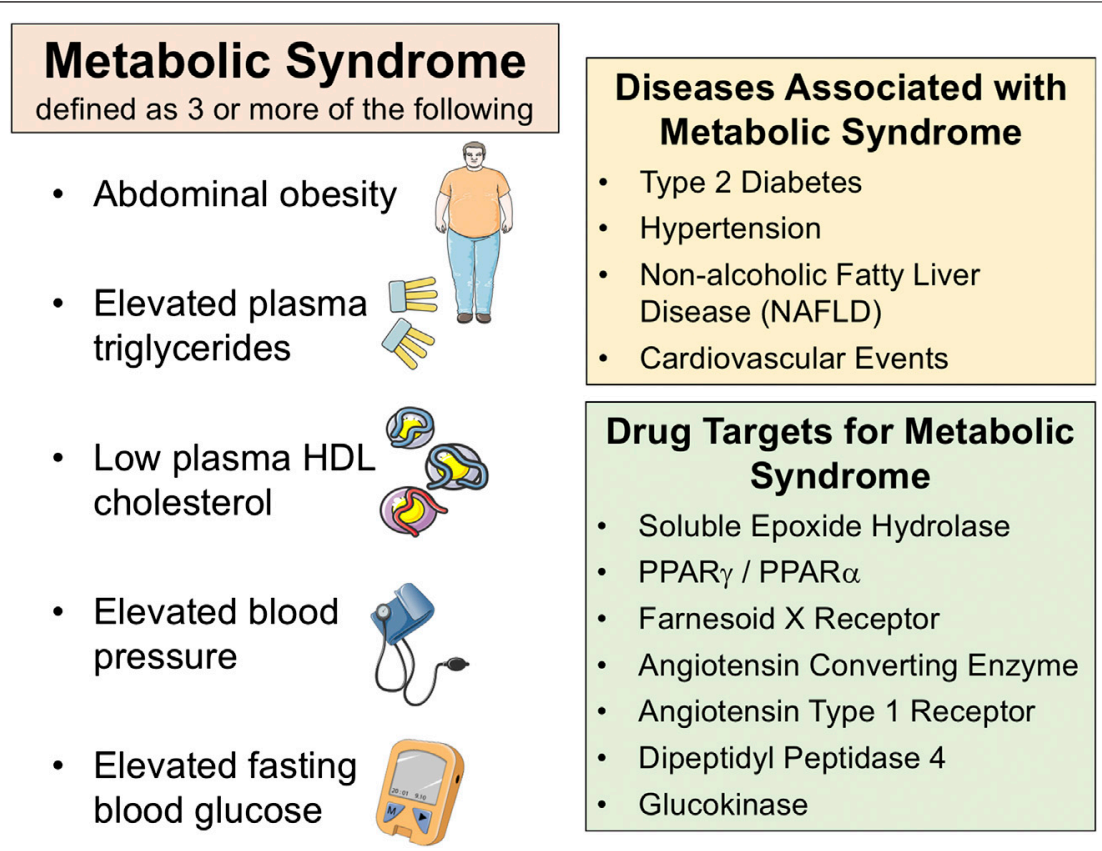

FIGURE 1 | Metabolic syndrome is defined as three or more of the following; abdominal obesity, elevated plasma triglycerides, low plasma HDL cholesterol, elevated blood pressure, elevated fasting blood glucose (left panel). There are several diseases associated with metabolic syndrome (right top panel). Several drug targets have been identified for metabolic syndrome and associated diseases (right bottom panel).

physiological regulatory systems due to excessive energy intake that provokes stressor stimuli that subsequently trigger inflammatory pathways (Dandona et al., 2005; Hotamisligil, 2006; Esser et al., 2014). Increases in plasma free fatty acids also plays a critical role in the pathogenesis of insulin resistance and inflammation in metabolic diseases (Alberti et al., 2005; Forbes and Cooper, 2013). Indeed, chronic inflammation is a hallmark of metabolic disease and its severity depends on the presence of different metabolic pathophysiological components (Dandona et al., 2005; Hotamisligil, 2006; Esser et al., 2014). Humans with metabolic diseases have increased plasma concentrations of tumor necrosis factor- $\alpha$ (TNF- $\alpha$ ), interleukin-6 (IL-6), IL-1 $\beta$, C-reactive protein and other inflammatory mediators (Dandona et al., 2005; Hotamisligil, 2006; Esser et al., 2014). Inflamed tissues in metabolic diseases include adipose, liver, kidney, and pancreas (Dandona et al., 2005; Hotamisligil, 2006; Esser et al., 2014). Experimental studies in metabolic disease animal models demonstrate substantial macrophage infiltration and increased cytokines in abdominal and peri-renal fat tissue, which could serve as a means for inflammatory cytokines to cause cardiovascular, neural, renal, and liver complications (Dandona et al., 2005; Esser et al., 2014; Bernardi et al., 2018). These findings support the notion that therapeutics that have anti-inflammatory actions could broadly combat metabolic diseases and associated complications.

Current therapeutics for metabolic diseases are varied in terms of ability to improve patient outcomes (Grundy et al., 2005; Grundy, 2006; Oseini and Sanyal, 2017). In addition, there are currently no approved drugs for the treatment of NAFLD (Oseini and Sanyal, 2017; Sumida and Yoneda, 2018). A first-line therapeutic approach for metabolic diseases is lifestyle changes including diet modification and physical activity (Grundy et al., 2005; Grundy, 2006). Nonetheless, often these lifestyle modifications are insufficient to normalize risk factors in patients, and treatment requires multi-drug therapy. A multidrug regimen or polypharmacy is a major problem for the treatment of patients with metabolic diseases due to poor patient compliance, side effects, and drug-drug interactions (Grundy, 2006; Noale et al., 2016; Alwhaibi et al., 2018).

Polypharmacy for metabolic diseases includes lipid lowering agents, anti-hypertensive agents, anti-diabetic agents, heart failure drugs, and anti-obesity therapies. Reduction of lowdensity lipoprotein (LDL) cholesterol by statins is a common treatment for patients with metabolic diseases. Statins are 3hydroxy-3-methyl-glutaryl-coenzyme A (HMG-CoA) reductase inhibitors that effect the rate limiting step in cholesterol biosynthesis (Grundy, 2006; Bianchi et al., 2007). Another lipid lowering approach in metabolic diseases is to inhibit intestinal cholesterol absorption with ezetimibe (Grundy, 2006; Bianchi et al., 2007). Angiotensin system inhibitors are commonly used to combat hypertension associated with metabolic diseases (Grundy et al., 2005; Bianchi et al., 2007). Angiotensin converting enzyme inhibitors or angiotensin receptor blockers not only lower blood pressure but can decrease heart and kidney disease progression in diabetes (Bianchi et al., 2007). Heart failure in metabolic disease is treated with diuretics, beta-adrenergic blockers, or calcium channel blockers (Dandona et al., 2005; Bianchi et al., 2007). 
Anti-diabetic agents include peroxisome proliferator-activated receptor- $\gamma(\operatorname{PPAR} \gamma)$ agonist insulin sensitizing agents, glucagon-like peptide-1 (GLP-1) receptor agonists, dipeptidyl peptidase-4 (DPP4) inhibitors, and sodium-glucose cotransporter-2 (SGLT-2) inhibitors (Bianchi et al., 2007). These anti-diabetic agents are effective in lowering blood glucose and hemoglobin Alc (HbAlc) levels (Grundy, 2006; Bianchi et al., 2007). Obesity can be treated with gastrointestinal lipase inhibitors, central nervous system acting drugs like serotonin $2 \mathrm{C}$ receptor agonists, or by bariatric surgery (Bianchi et al., 2007). A primary therapeutic approach for metabolic diseases has been to identify and treat each symptom or condition separately. This approach leads to several drugs being prescribed to patients with metabolic diseases.

Patients with metabolic diseases have a high rate of polypharmacy and this is a growing concern in the elderly population (Grant et al., 2003; Noale et al., 2016; Alwhaibi et al., 2018). For example, when polypharmacy is defined as at least five drugs being prescribed, the rate of polypharmacy reaches levels as high as $60 \%$ in patients over 65 years old with non-insulin dependent type 2 diabetes (Noale et al., 2016; Alwhaibi et al., 2018). The majority of these diabetics are on at least one anti-diabetic drug, not less than one anti-hypertensive drug, and a lipid lowering statin drug (Grant et al., 2003; Grundy, 2006; Noale et al., 2016; Alwhaibi et al., 2018). Although compliance and drug-drug interactions are issues with polypharmacy, a major issue that leads to suboptimal adherence by patients are side effects associated with one or more drugs (Grant et al., 2003). PPAR $\gamma$ agonists are an example of an effective anti-diabetic drug with a side effect that decreased compliance and prescriptions. Edema associated with thiazolidinedione (TZD) PPAR $\gamma$ agonist use led to a problem with patient compliance and a warning label for use in heart failure (Guan et al., 2005). Consequently, these side-effects resulted in a drastic reduction in the use of PPAR $\gamma$ agonists in the treatment of type 2 diabetes (Stafylas et al., 2009). Another significant issue is the utilization of central nervous system antiobesity drugs and side effects associated with these drugs. This concern came to light with the introduction of the cannabinoid type 1 (CB1) receptor antagonist rimonabant in 2006 (Christensen et al., 2007; Després et al., 2008). Rimonabant was effective in reducing appetite through inhibition of central nervous system CB1 receptors combined with decreasing blood glucose as well as fat and lipid metabolism via blocking peripheral CB1 receptors (Christensen et al., 2007; Després et al., 2008). Unfortunately, major side effects for rimonabant were depression and suicide that led to it being withdrawn in 2008 (Christensen et al., 2007; Després et al., 2008). Taken as a whole, metabolic diseases are treated with anti-obesity, anti-diabetic, lipid lowering, and anti-hypertensive drugs that have central nervous system and peripheral actions that lead to significant polypharmacy concerns.

A potential solution to polypharmacy in metabolic diseases is combining multiple drugs or invent drugs with multiple actions to combat metabolic diseases. Consequently, there is growing interest in developing novel therapeutic strategies that could target multiple metabolic disease components to provide a comprehensive treatment approach (Rollason and Vogt, 2003; Morphy and Rankovic, 2005). Developing a drug that lowers plasma lipids, decreases inflammation, decreases blood pressure, and lowers blood glucose levels would be ideal to treat metabolic diseases. Currently, there are no approved drugs that can reliably reduce multiple conditions associated with metabolic diseases over the long-term (Grundy et al., 2005; Grundy, 2006; Handelsman and Jellinger, 2011).

Interestingly, there are several metabolic disease drugs that have actions at multiple targets or have multiple therapeutic actions that could serve as a starting point for developing novel bifunctional molecules to treat metabolic diseases. These drugs include statins, metformin, PPAR agonists, and farnesoid X receptor (FXR) agonists. Statins have a primary action to lower LDL-c levels in metabolic diseases (Dandona et al., 2005; Grundy et al., 2005). These lipid lowering actions are due to statins ability to inhibit HMG-CoA reductase (Dandona et al., 2005; Grundy et al., 2005). Atorvastatin in particular has also been demonstrated to enhance hepatic insulin sensitivity and signaling through undetermined mechanisms (Dandona et al., 2005; Grundy et al., 2005). There is also evidence that statins have a direct antiinflammatory action since statins lower C-reactive protein levels (Dandona et al., 2005). Another potential starting point is the biguanide metformin that is widely prescribed for type 2 diabetes and MetS (Dandona et al., 2005; Bianchi et al., 2007). Metformin lowers blood glucose and HbAlc levels and prevents weight gain (Bianchi et al., 2007). The primary action for metformin is to lower hepatic glucose output through adenosine monophosphate (AMP) kinase activation (Bianchi et al., 2007). Another positive aspect is that metformin decreases circulating plasminogen activator inhibitor-1 levels which could combat cardiovascular diseases associated with type 2 diabetes and MetS (Dandona et al., 2005; Bianchi et al., 2007). PPAR $\gamma$ agonists such as rosiglitazone are used as insulinsensitizing agents to treat type 2 diabetes (Bianchi et al., 2007). Because PPAR $\gamma$ agonists act as a ligand regulated transcription factor these drugs regulate the expression of many genes that have a myriad of actions. One of the actions that these thiazolidinedione PPAR $\gamma$ agonists have is to decrease inflammatory genes to prevent atherosclerotic complications associated with type 2 diabetes (Bianchi et al., 2007). There have been attempts made to develop drugs that act on multiple PPARs including PPAR $\alpha$, PPAR $\gamma$, and PPAR $\delta$ for treating metabolic diseases (Dandona et al., 2005; Bianchi et al., 2007; Jain et al., 2018). Regrettably, these dual-acting PPARs have failed to become approved for treating metabolic diseases. Nevertheless, the strategy to introduce PPAR $\gamma$ activity has been excessively used in various approaches to multi-target drugs for MetS and were excellently reviewed by Ammazzalorso et al. (2019) Although not currently approved for humans, FXR agonists are being developed to treat metabolic diseases like NAFLD and fibrotic diseases (Ali et al., 2015; Oseini and Sanyal, 2017; Sumida and Yoneda, 2018). FXR activation reduces hepatic fat accumulation and has been demonstrated to have anti-fibrotic and anti-inflammatory actions (Oseini and Sanyal, 2017; Sumida and Yoneda, 2018). Obeticholic acid is an 
FXR agonist that has entered clinical trials for non-alcoholic steatohepatitis (NASH) and NAFLD; however, this FXR agonist has the unwanted effect of increasing total cholesterol levels and increasing the HDL-c to non-HDL-c ratio (Mudaliar et al., 2013; Han, 2018). Nevertheless, a common denominator for this group of metabolic disease drugs that could serve as a starting point to develop multi-target drugs is their ability to combat inflammation. Novel bifunctional molecules described in this review build on this anti-inflammatory action and will have the capacity to impact multiple factors including blood pressure, lipid and triglyceride levels, and insulin signaling in metabolic diseases like MetS, type 2 diabetes and NAFLD.

Rational approaches to design multi-target drugs have become popular in the last decade (Morphy and Rankovic, 2005). Most often, they comprise small molecule design which addresses two or more targets. As mentioned before, a multi-target drug potentially exhibits few side effects than a combination of drugs, leading to an improved adherence of the patients (Morphy and Rankovic, 2005). The first and crucial step is the identification of a suitable target combination. It seems to be apparent to choose targets modulating the different components of the MetS which are addressed by established drugs used in treatment of metabolic disorders. However, not every target combination represents a promising approach for the development of a multi-target ligand. First, the chemical tractability has to be taken in account, which is obviously high if the targets of interest accommodate chemically similar endogenous ligands. However, several exceptions exist, where targets with very different ligands can be addressed by one drug. The most prominent example are dual modulators of angiotensin II receptor subtype 1 (AT1) and PPAR $\gamma$, which is discussed later. Second, a promising target combination exhibits a synergistic effect, contributing to the efficacy and safety of the multi-target drug. The systematic identification of synergistic target combinations, well-established in cancer and antibiotics, is still in its infancy in the field of metabolic diseases (Proschak et al., 2019).

The medicinal chemistry approaches to designed multi-target ligands can be classified in three types: linked, fused, and merged pharmacophores (Morphy and Rankovic, 2005; Proschak et al., 2019). Linking of two (or more) pharmacophores by a flexible linker often leads to compounds exhibiting sufficient in vitro potency toward all targets of interest, however the larger molecular weight combined with an increased number of free rotatable bonds have a negative effect on pharmacokinetics (Mor phy and Rankovic, 2006). Therefore, the identification of a pharmacophore element to enable the fusion of two ligands usually leads to smaller molecules, while the identification of a merged pharmacophore for both targets can be regarded as the most promising way to develop a multi-target ligand exhibiting a promising pharmacodynamics and pharmacokinetic profile.

Multi-target ligands have varying $\mathrm{IC}_{50}$ and $\mathrm{EC}_{50}$ that are determined by in vitro means. Yet, the ability to translate to in vivo systems is more complicated than single target ligands. A primary question that remains unanswered is whether multitarget ligands can engage two targets in vivo at the same time. The ability for multi-target ligands to engage two targets in vivo at the same time would depend on the type of multi-target molecule, cellular proximity of the targets, and binding properties to the targets. Linked multi-target ligands with excellent binding properties for two targets in very close cellular proximity is the most likely scenario where both targets could be engaged in vivo at the same time. A more likely scenario is that a certain amount of multi-target molecule engages each target separately with a particular plasma level required for proper modulation of the two targets. In the end, extensive in vivo evaluation is needed for assessing proper target engagement of multi-target ligands. Multi-target ligands described in this review have been used at doses in animal disease models that have been verified to achieve proper in vivo target engagement.

This review article aims at summarizing several examples of small molecule multi-target ligands for metabolic diseases. We particularly try to explain the rationale behind the choice of a certain target combination. Furthermore, we address the challenges which arise from the design and optimization of multi-target ligands and their potential in the treatment of MetS.

\section{sEH and PPAR $\gamma$}

The arachidonic acid (AA) cascade presents one of the major pathways for the progression of pain and inflammation signals in the human body. Therefore, the metabolites, enzymes and receptors of this cascade are excellent therapeutic targets for treatment of the MetS and inflammatory diseases in general (Imig and Hammock, 2009). Throughout the Cytochrome P450 (CYP)branch AA gets metabolized into either pro-inflammatory hydroxyeicosatrienoic acid 20-HETE or to anti-inflammatory epoxyeicosatrienoic acids (EETs) (Spector, 2009). The positive effects of the different EETs are well described in literature (Spector and Norris, 2007; Shen and Hammock, 2012; Morisseau and Hammock, 2013; Campbell et al., 2017), but through further metabolization their beneficial characteristics are decreased. In humans, EETs are predominantly metabolized via the soluble epoxide hydrolase (sEH, EPHX2) pathway (Morisseau and Hammock, 2013). While epoxide hydrolases in general are a group of enzymes that converts epoxide containing compounds into their corresponding diols (Morisseau, 2013), the sEH in particular converts EETs into the less biological active dihydroxyepoxyeicosatrienoic acids (DHETs). Furthermore, the $\mathrm{sEH}$ forms a domain-swapped homodimer, which is encoded by the gene EPHX2, located on chromosome 8 (Tanaka et al., 2008). The protein is a bifunctional enzyme that exhibits two different catalytic sites. The already described hydrolase domain is linked via a proline rich linker to a phosphatase domain whose physiological role is still under investigation (Kramer and Proschak, 2017). In mammalian tissue the $\mathrm{sEH}$ is widely spread, including organs like liver, kidney, lungs, heart, brain, spleen (Newman et al., 2005). The distribution of the protein is tissue dependent on subcellular level, and the sEH can be found either in the cytosol or additionally in the peroxisomes (Przybyla-Zawislak et al., 2003).

As mentioned before, peroxisome proliferator-activated receptors (PPARs) are ligand-activated transcription factors of the nuclear receptor family, which belongs to the superfamily of nuclear receptors (Michalik et al., 2006). So far three isoforms are 
<smiles>O=C(NC1CCC(Oc2ccc(C(=O)O)cc2)CC1)NC12CC3CC(CC(C3)C1)C2</smiles>

$1(t-A \cup C B)$

$\mathrm{sEH} I \mathrm{IC}_{50}: 1.3 \mathrm{nM}$

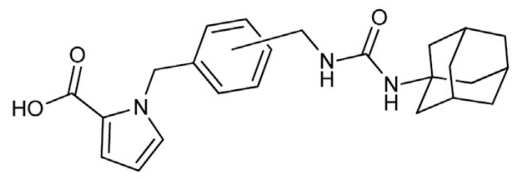

3

ortho:

sEH IC $50: 178 \mathrm{nM}$

PPARg activation: $45 \% @ 10 \mu \mathrm{M}$

meta:

sEH IC $50: 304 \mathrm{nM}$

PPARg activation: 16\%@10 $\mu \mathrm{M}$

para:

sEH IC $50: 73 \mathrm{nM}$

PPARg activation: 18\%@10 $\mu \mathrm{M}$<smiles></smiles>

2 (Rosiglitazone) PPARg EC $_{50}: 43 \mathrm{nM}$<smiles>CCC(=Cc1ccc(C(=O)NCc2ccc(OC)cc2C(F)(F)F)cc1)C(=O)O</smiles>

4 (RB394)

sEH IC $50: 0.3 \mu \mathrm{M}$

PPARg $\mathrm{EC}_{50} 0.3 \mu \mathrm{M}$ (max. 160\%)

FIGURE 2 | Selective sEH inhibitor t-AUCB, selective PPAR $\gamma$ agonist Rosiglitazone (top), and dual sEH/PPAR $\gamma$ modulators.

described in literature: $\alpha, \beta / \delta$ and $\gamma$. They all form a heterodimer with the retionoid-X-receptor (RXR), which in turn is activated through 9-cis retinoic acid (Germain et al., 2006). PPAR $\gamma$ itself plays a major role in regulation of lipid metabolism, glucose homeostasis, adipogenesis, and in several inflammatory processes and was therefore described as the master transcriptional regulator for the development of adipose cells (Tontonoz and Spiegelman, 2008).

The sEH metabolites EETs and PPAR $\gamma$ signaling are tightly interconnected. Inhibition of sEH leads to increased EET levels, which were identified as endogenous ligands of $\operatorname{PPAR} \gamma$, have angiogenetic properties and increase vascular endothelial growth factor (VEGF) (Liu et al., 2005; Spector, 2009). Thus, Xu and Hammock hypothesized that the mechanism underlying the effect of the sEH inhibitor $t$-AUCB (1) (Hwang et al., 2007) on epithelial progenitor cells (EPCs) was the EETs-PPAR $\gamma$ pathway. This pathway was supported by the sEH-mediated angiogenetic effects, which in turn increases VEGF and Hypoxia-inducible factor 1-alpha (HIF-1 $\alpha)$, triggers EPC migration and proliferation and in the end could lead to angiogenesis (Xu et al., 2013).

In 2012 Imig and Hammock studied the effects of the selective PPAR $\gamma$ agonist Rosiglitazone (2) (Willson et al., 2000) in combination with $t$-AUCB (1) (Figure 2) in order to decrease renal injury in spontaneously hypertensive obese (SHROB) rats (Imig et al., 2012). SHROB, also called Koletzky rats features a nonsense mutation in the leptin receptor. This mutation impairs the capacity of leptin to regulate food intake which causes dramatic weight gain and metabolic disorders. SHROB rats are homozygous for this mutation, whereby they show monogenetic obesity in combination with a hypertensive background. For this background several phenotype aspects are descried, such as insulin resistance, obesity, hypertension, increased plasma triglyceride levels, fatty liver and glucose intolerance (Ernsberger et al., 1999; Molinar-Toribio et al., 2014). Collectively, these features make SHROB rats an excellent and relevant model for the study of metabolic syndrome. The authors described that the combination of $t$-AUCB (1) and Rosiglitazone (2) is very effective with regards to preventing kidney damage. Both compounds lower blood pressure and blood glucose levels in a comparable manner, however the effects were not additive when administered together. Futhermore, $t$-AUCB (1) independently showed positive effects in preventing renal injury in contrast to the PPAR $\gamma$ modulator which showed positive decreasing effects on free fatty acids, plasma lipids and inflammation accompanied with an improved $\mathrm{K}_{\mathrm{ATP}}$-mediated vasodilation. These findings lead the authors to the conclusion that the single application of an sEH-I or a PPAR $\gamma$ modulator is beneficial, but in regard to the multi disease characteristics of the MetS, the combination is even superior (Imig et al., 2012).

These studies together underline the potential for the development of a combined sEH/PPAR $\gamma$ modulator for the treatment of the MetS. The first attempt in that direction was done is 2002 when Buscato et al. described the first dual modulators 3 of sEH and PPARs as potential agents for the treatment of features related to the metabolic syndrome (la Buscató et al., 2012). Starting from an combinatorial approach they combined known pharmacophores of sEH (hydrophobic 


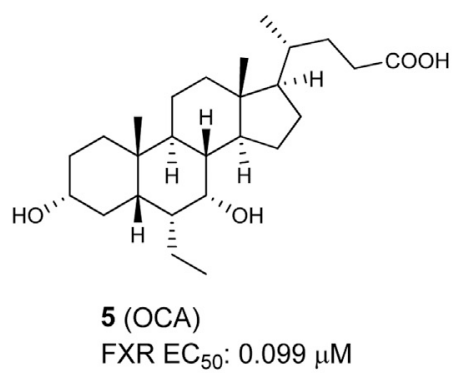<smiles>[R16]COc1cccc(/C=C/c2ccc(OCc3c(-c4c(Cl)cccc4Cl)noc3C(C)C)cc2Cl)c1</smiles>

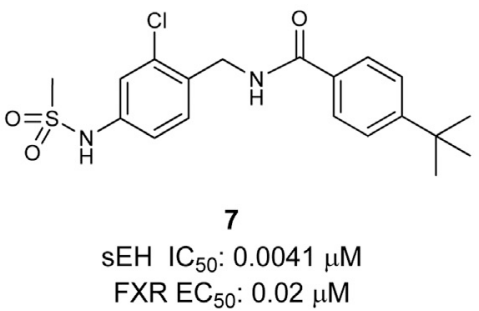

FIGURE 3 | Selective FXR agonists OCA and GW4064 (top), and dual sEH/FXR modulator.

urea moiety) and PPAR (acidic headgroup) into one molecule. Despite other combination of dual sEH-I with PPAR $\alpha$ - or PPAR $\delta$-modulators, they discovered the first dual sEH/PPAR $\gamma$ modulators, which were able to inhibit $\mathrm{sEH}$ with moderate potency and partially activate PPAR $\gamma$.

Blöcher et al. discovered with $N$-benzyl benzamides a novel scaffold of orally available dual sEH/PPAR $\gamma$ modulators (Blöcher et al., 2016). By analyzing the structures of previously described PPAR $\gamma$ modulators (GSK1997132B (Sime et al., 2011), KCL (Nomura et al., 2003)), and the sEH inhibitor GSK2188931B (Kompa et al., 2013), they created a series of dual modulators based on the common $N$-benzyl benzamide substructure. The lead compound RB394 (4) showed submicromolar potency on both targets, good water solubility $(500-375 \mu \mathrm{M})$ as well as metabolic stability in rat liver microsomes. These favorable properties were accompanied by an excellent in vivo pharmacokinetic profile in mice, qualifying RB394 (4) as a pharmacological tool for diabetic animal models (Blöcher et al., 2016).

The in vivo profile of RB394 (4) was further characterized by Hye Khan et al. (2018). They tested the dual modulator in rat models of the MetS and type 2 diabetes and could demonstrate its potential for targeting multiple risk factors. Two pre-clinical rat models were used in this study: SHROB- and ZSF1 (Zucker fatty/Spontaneously hypertensive heart failure F1 hybrid)-rats. In SHROB rats RB394 attenuated the development of insulin resistance, hypertension, hyperlipidemia and decreases kidney injury. In both rat models, RB394 effectively reduces kidney injury such as renal fibrosis and improves liver complications and steatosis. It could also be shown that RB394 in diabetic ZSF1 rats reduces hyperglycemia, hyperlipidemia and insulin resistance. Even though RB394 improved the insulin resistance it did not show any effect of altering the body weight, which in literature was described as interrelated (Eckel et al., 2005). The authors explained this findings thereby that the body weight gain initiated by PPAR $\gamma$ agonists could be caused by edema, which result of PPAR $\gamma$ mediated stimulation of kidney epithelial sodium channels (ENaCs) (Shah and Mudaliar, 2010). sEH-I alone did not show any effect on the body weight change, but they seem to have an effect on the ENaCs. EETs block ENaCs (Pavlov et al., 2011) and, therefore, no PPAR $\gamma$ activation caused body weight gain was observed, which, furthermore, highlights the potential of a dual modulator. Additionally, the preventive and reducing effects on insulin resistance and hyperinsulinaemia as well as the lipid-lowering effects in those rat models are due to the combined sEH/PPAR $\gamma$ pharmacophores in RB394. Finally, the dual modulator reduces MCP-1 (monocyte chemoattractant protein-1) excretion, renal immune cell infiltration and TGF- $\beta$ (transforming growth factor beta) expression which in summary lead to a reduced renal inflammation. The renal protective effects were confirmed mouse unilateral ureteral obstruction (UUO) model. In this setting, RB394 outperformed a selective sEH-I and a selective PPAR $\gamma$ agoinist rosiglitazone, as well as their combination (Stavniichuk et al., 2020).

These findings support the hypothesis that the combination of an sEH inhibitor with a selective PPAR $\gamma$ agonist in one molecule could be beneficial for the treatment of type 2 diabetes, related complications, and potentially the MetS in general. The dual sEH/ $\operatorname{PPAR} \gamma$ modulator also possibly extends the applicability of sEH inhibitors in context of cancer promoting effects. In a hallmark publication by Panigrahy et al. epoxyeicosanoids are responsible for mild promotion of metastasis (Panigrahy et al., 2012). The 
effects were mainly mediated by cyclooxygenase (COX)-derived metabolites of EETs (Rand et al., 2017) and can be reversed by the application of a dual sEH/COX inhibitor (Zhang et al., 2014). Several publications demonstrated that $\operatorname{PPAR} \gamma$ activation suppresses COX-2 expression (Mendez and LaPointe, 2003) and a dual sEH/PPAR $\gamma$ could potentially circumvents the tumor promoting effects of (COX)-derived metabolites of EETs.

\section{sEH and FXR}

FXR (NR1H4) is a nuclear bile acid (BA) receptor (Makishima et al., 1999; Cariou and Staels, 2007). As a transcription factor, FXR binds to the response elements of its target genes either as monomer, as homodimer or as heterodimer with RXR. FXR regulates the transcription of genes that, among others, are involved in inflammation and glucose and lipid homeostasis (Carr and Reid, 2015). It is highly expressed in liver, intestine, kidney and adrenal glands, but it is also expressed in white adipose tissue and is induced during in vitro adipocyte differentiation (Cariou and Staels, 2007). The physiological role of FXR is liver protective, as it is an enterohepatic regulator of bile acid homeostasis (Massafra et al., 2018). The role of FXR in the context of the metabolic syndrome has been intensively reviewed in literature, underlining its potential for the treatment of the MetS (Cariou and Staels, 2007; Ma and Patti, 2014).

Generally two types of FXR agonists could be found, first bile acids and their semi-synthetic analogues, e.g., obeticholic acid (6a-ethyl-chenodeoxycholic acid OCA, 6-EDCA, 5) (Pellicciari et al., 2002), and second non-steroidal compounds, such as the isoxazole derivative GW4064 (6) (Maloney et al., 2000) (Figure 3). These structures should be seen as representatives for both classes. Recently, OCA has been approved for the treatment of primary biliary cholangitis. Furthermore, representatives of both, bile acid analogues and non-steroidal FXR agonists like nidufexor (Chianelli et al., 2020) or tropifexor (Tully et al., 2017) are under clinical investigation for treatment of NAFLD and NASH (Mudaliar et al., 2013; Neuschwander-Tetri et al., 2015). The disease complex of NAFLD/NASH is considered to be a hepatic manifestation of the MetS (Petäjä and YkiJärvinen, 2016). NASH is associated with numerous risk factors, such as obesity and type 2 diabetes mellitus (T2DM) (Rivera, 2008).The clinical trials with OCA have proven FXR as a target for the treatment of fatty liver disorders (Mudaliar et al., 2013; Neuschwander-Tetri et al., 2015). In addition, several studies in mice with high-fat-diet-induced fatty liver could show that a sEH inhibition, achieved either by pharmacological inhibition or by genetical deletion, has positive outcomes on the disease. These studies point out that in NAFLD/NASH the CYP epoxygenase pathway is an important regulator (Liu et al., 2012; Schuck et al., 2014; Mangels et al., 2016).

Taken together the anti-inflammatory and anti-steatotic effects of a sEH inhibitor and the positive effects after FXR activation in NASH with an FXR agonist, it shows clearly the potential of a dual sEH/FXR modulator in this disease. In this regard, the first dual modulator 7 was published in 2017 by Schmidt et al., 2017 Following a combinatorial approach, the authors merged the structures of a previously reported $\mathrm{sEH}$ inhibitor (Kompa et al., 2013) with an selective FXR partial agonist (Merk et al., 2014b). After several structural optimizations and a bioisosteric replacement strategy they yielded an efficacious dual modulator (see Figure 3). This dual modulator is able to partial activate FXR target gene expression and shifts the EET/DHET ratio via sEH inhibition toward the more favorable EETs. Furthermore, the compound was proven active in vivo in a male wild-type C57BL6/J mice-study (Schmidt et al., 2017).

The efficacy of the dual sEH/FXR modulator 7 was demonstrated in two models of NASH-the streptozotocininduced mice and the choline-deficient high-fat diet induced mice (Takahashi et al., 2012). The dual sEH/FXR modulator 7 reduced the hepatic steatosis and fibrosis. Furthermore, it exhibited a pronounced anti-inflammatory effect, thereby demonstrating excellent efficacy in the complex setting of NASH (Hye Khan et al., 2019).

\section{FXR and PPARs}

Besides the already mentioned positive effects of the selective FXR ligand OCA on many parameters of MetS in the FLINT trial (Neuschwander-Tetri et al., 2015), in the last decades intensive research has been done on the relation between FXR and the peroxisome proliferator-activated receptors, as reviewed in different publications (Cave et al., 2016; Lee, 2016; Preidis et al., 2017). From these reviews we want to highlight a few of the study's which are related to the MetS.

\section{FXR and PPARa}

PPARa (NR1C1) is highly expressed in the liver and brown fat tissue, followed by heart, kidney and small intestine (Kersten, 2014). It could be described as a master transcription factor for the metabolization of lipids in the fasted state or under conditions of energy shortage (Evans et al., 2004). The liver is the key organ in transitions between feeding and fasting states, by changing the system from energy accumulation to energy-consumption (Rui, 2014). PPARa in this regard increases the oxidation of fatty acids in the fasted state (Kersten, 2014). On the other hand, in the fed state, FXR is activated. While both nuclear receptors seem to act opposite to each other in their metabolic functions, there is clear evidence in literature that they have the same effect in suppressing lipogenesis (Watanabe et al., 2004; Savkur et al., 2005; Inagaki et al., 2007; Kersten, 2014). This could be beneficial in the case of fatty liver. McGarry suggested a vicious circle: increased steatosis levels results in insulin resistance, this in turn leads to even more steatosis all of which is triggered by an increase in lipogenesis in the insulin-resistant liver (McGarry, 1992). Moore proposed that in response to the activation of different nuclear receptors (e.g., FXR and maybe PPARa), lipogenesis is suppressed (Moore, 2012). This improves fatty liver and ameliorate insulin sensitivity and in turn further inhibits lipogenesis. In this way the vicious cycle would be reversed into a beneficial one. Because PPAR $\alpha$ and FXR are activated in different states of the nutrientbased energy uptake and consumption, their interplay in the healthy state is well orchestrated to ensure that metabolic flux and energy balance is regulated appropriately (Preidis et al., 2017). In 


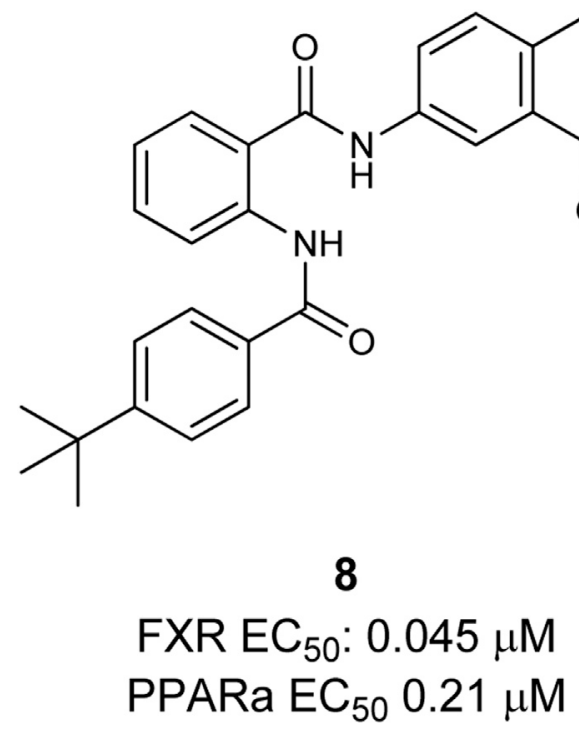

FIGURE 4 | Dual FXR/PPAR a agonist.

the unhealthy state, this energy balance is malfunctioning and, therefore, treatment with PPARa- and FXR-antagonist or perhaps a dual ligand could be beneficial if it is pharmacologically possible to target each nuclear receptor in the adequate state.

The first dual PPARa/FXR partial agonist $\mathbf{8}$ was descripted by Merk et al. (Figure 4). Compound $\mathbf{8}$ was found by characterizing their former published selective FXR modulating anthranilic acid derivatives on the off-targets: PPARs $(\alpha, \beta / \delta, \gamma)$ (Merk et al., 2014a; Merk et al., 2014b). Based on these findings a novel structure-activity relationship (SAR) study was conducted in order to optimize selectivity and potency toward the PPARs, leading to the discovery of potent and selective PPAR agonists. In this way the dual PPARa/FXR agonist was developed. This partial agonist $\mathbf{8}$ is selective over other subtypes of PPAR, highly potent on both targets, and exhibits only slight toxicity (Merk et al., 2015).

All in all, the authors concluded that a dual PPARa/FXR modulator, amalgamating the positive effects of FXR and PPARa activation, could be highly beneficial and offer a possibility for the treatment of lipid associated, metabolic abnormalities. This initial study could be a good starting point for further optimization on this promising new lead structure.

\section{FXR and PPAR $\gamma$}

Besides the already descripted relation between PPAR $\alpha$ and FXR, in literature, a connection between FXR and PPAR $\gamma$ has also been described. Previous studies have shown that FXR ligands are able to induce PPARa mRNA levels in human hepatic cells (Pineda Torra et al., 2003). In a rodent model of liver cirrhosis, Fiorucci et al. have shown that FXR ligands regulate PPAR $\gamma$ gene expression and, furthermore, that both nuclear receptors act synergistically in regulation of profibrogenetic events in human hepatic stellate cells (HSCs) (Fiorucci et al., 2005).
HSCs or perisinusoidal cells are pericytes, which are involved in liver fibrosis. In addition, this study demonstrated that natural (bile acid: Chenodeoxycholic acid (CDCA)) as well as synthetic (GW4064) FXR ligands induce the expression of PPAR $\gamma$ in HSCs. While in liver diseases a down regulation of PPAR $\gamma$ is observed, the authors could show that an FXR ligand protects against that mechanism and also that the FXR ligand improves the antifibrotic activity of PPAR ligands. This is hint for a cross-talk between both nuclear receptors which could limit the activation of HSCs. Until now, no dual FXR/PPAR $\gamma$ ligand has been described in the literature. However, the study from Fiorucci et al. has shown a development of such a ligand could be worthwhile.

\section{ACE and DPP4}

As the population numbers of T2DM continues to rise, the need for identifying pharmacological tools to conquer this disease is also increasing. A very prominent class in this context are DPP4 inhibitors, also called Gliptins (Scheen, 2015). These molecules have the potential to increase glucose uptake by inhibiting the DPP4 enzyme and preserving the action of GLP-1. GLP-1 is a peptide-hormone which belongs to the incretins and is able to liberate insulin in a dose dependent manner after oral glucose uptake. Furthermore, GLP-1 suppresses the formation of glucagon (Grigoropoulou et al., 2013). In the human body GLP-1 is rapidly degraded after formation by DPP4 which makes it challenging, but not impossible, to be targeted directly (Tomlinson et al., 2016). First GLP-1 agonist, semaglutide, was found to be very effective and entered the market (Dhillon, 2018). However, DPP4 as the GLP-1 degrading enzyme is still a valuable target to face T2DM. DPP4, also known as CD26, is an exopeptidase which cleaves proline or alanine dipeptides from the $\mathrm{N}$-terminus of proteins and peptides. This cleavage leads to the building of new biological active peptides or inactivates those proteins/peptides. DPP4 is expressed in various tissues and can either be found membrane bound or as a soluble circulating form (sDDP4) liberated from the plasma membrane without its intracellular tail and transmembrane regions (Durinx et al., 2000). Several gliptins have already come onto the market for the treatment of T2DM. This class of inhibitors exhibit different side effects such as skin reactions or gastrointestinal problems (Charbonnel et al., 2006; Nelson et al., 2014; Scheen, 2018). This underlines as well the potential of inhibiting DPP4, but also the need for new and safer inhibitors for this enzyme.

While DPP4 inhibitors are effective against hyperglyceamia, for the treatment of hypertension ACE (angiotensin converting enzyme) inhibitors have been shown to be efficient and safe form of treatment. ACE inhibitors are a class of antihypertensive drugs, which is primarily used for the treatment of cardiovascular (e.g., congestive heart failure (CHF)), or renal diseases (Regulski et al., 2015). Prominent examples are the substances captopril, enalapril or benazepril. This class of molecules acts through the inhibition of the angiotensin converting enzyme and through this mechanism are able to decrease activity of the reninangiotensin-aldosterone system (RA(A)S). RAS controls the arterial blood pressure, electrolyte balance, and cardiovascular, adrenal and renal functions (Ferrario and Strawn, 2006; Regulski et al., 2015). To do so, the proteolytic enzyme renin is released in 
TABLE 1 | Beneficial effects of combinations of pharmacological targets.

\begin{tabular}{|c|c|c|c|c|c|}
\hline $\begin{array}{l}\text { Target } \\
\text { combination }\end{array}$ & sEH/PPAR $\gamma$ & DPP4/MCH-1R & DPP4/GPR119 & DPP4/ACE & \\
\hline $\begin{array}{l}\text { Positive implications } \\
\text { for MetS }\end{array}$ & $\begin{array}{l}\text { Antidiabetic, cardioprotective, } \\
\text { renoprotective, blood pressure- } \\
\text { lowering }\end{array}$ & $\begin{array}{l}\text { Antidiabetic, } \\
\text { weight loss }\end{array}$ & $\begin{array}{l}\text { Antidiabetic, glucose } \\
\text { homeostasis }\end{array}$ & $\begin{array}{l}\text { Antidiabetic, treating } \\
\text { hyperglycemia and hypertension }\end{array}$ & \\
\hline $\begin{array}{l}\text { Target } \\
\text { combination }\end{array}$ & sEH/FXR & FXR/PPAR $\alpha$ & FXR/PPAR $\gamma$ & PPAR $\gamma / A T 1$ & PPAR $\gamma / G K$ \\
\hline $\begin{array}{l}\text { Positive implications } \\
\text { for MetS }\end{array}$ & Anti-inflammatory, anti-steatotic & $\begin{array}{l}\text { Suppressing } \\
\text { lipogenesis }\end{array}$ & $\begin{array}{l}\text { Antifibrotic, liver } \\
\text { protective }\end{array}$ & $\begin{array}{l}\text { Antihypertensive, } \\
\text { antidiabetic }\end{array}$ & $\begin{array}{l}\text { Improves insulin resistance, } \\
\text { reducing blood glucose levels }\end{array}$ \\
\hline
\end{tabular}<smiles>N[C@@H](CC(=O)N1CCn2c(nnc2C(F)(F)F)C1)Cc1cc(F)c(F)cc1F</smiles>

9 (Sitagliptin)

DPP4 $\mathrm{IC}_{50}: 20 \mathrm{nM}$

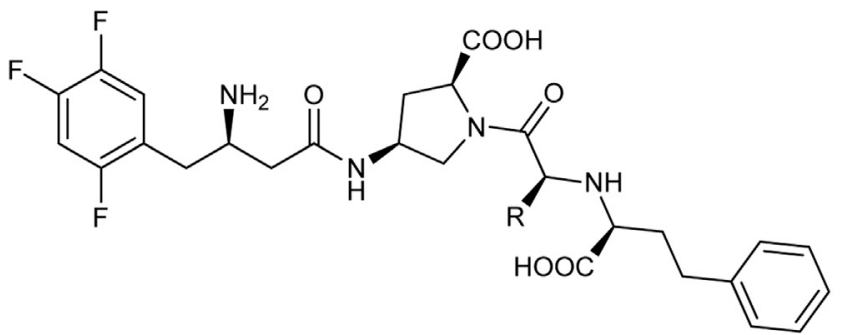<smiles>C[C@H](N[C@@H](CCc1ccccc1)C(=O)O)C(=O)N1CCCC1C(=O)O</smiles>

10 (Enalaprilat)

ACE IC $50: 2.5 \mathrm{nM}$

\begin{tabular}{|c|c|}
\hline 11 & \\
\hline $\mathrm{R}=\mathrm{Me}:$ & $\mathrm{R}=n-\mathrm{Pr}:$ \\
\hline $\begin{array}{l}\text { ACE IC } 50: 258 \mathrm{nM} \\
\text { DPP4 IC } \mathrm{IC}_{50}: 255 \mathrm{nM}\end{array}$ & $\begin{array}{l}\text { ACE IC } 50: 51 \mathrm{nM} \\
\text { DPP4 IC } \text { IC }_{50}: 67 \mathrm{nM}\end{array}$ \\
\hline $\mathrm{R}=\mathrm{Et}:$ & $\mathrm{R}=n-\mathrm{Bu}:$ \\
\hline $\begin{array}{l}\text { ACE IC } I_{50}: 8.6 \mathrm{nM} \\
\text { DPP4 } \mathrm{IC}_{50}: 57 \mathrm{nM}\end{array}$ & $\begin{array}{l}\text { ACE IC } I_{50}: 279 \mathrm{nM} \\
\text { DPP4 } \mathrm{IC}_{50}: 102 \mathrm{nM}\end{array}$ \\
\hline
\end{tabular}

FIGURE 5 | Selective DPP4 inhibitor Sitagliptin, selective ACE inhibitor Enalaprilat, and dual ACE/DPP4 inhibitor.

the kidney. There, it tranforms its substrate angiotensinogen into angiotensin I (Ang I). AngI is then further cleaved bye ACE to the physiologically active angiotensin II (Ang II) (Pacurari et al., 2014). Renin is released for example in response to low blood pressure, hyponatremia, or potassium depletion (Regulski et al., 2015). Therefore, the inhibition of the conversion of Ang I to Ang II leads very general to a decrease in blood pressure and vascular tone. Moreover, it has been shown that ACE inhibitors are able to reduce the progress of diabetic nephropathy and provide renovascular protection (Feng et al., 2019).

Wang et al. reported in 2012 the discovery of an egg protein hydrolysate, which shows DDP4- and ACE-inhibitory activity (Wang et al., 2012). Following an in silico approach to identify a protein that is able to modulate relevant MetS-targets, the authors analyzed protein digests and calculated their bioactivity, leading to the finding of the egg protein lysozyme NWT-03. After digestion with alcalase, this protein has the potential to act as a protein precursor for ACE-inhibitory peptides. By confirming the ACE-inhibition activity in a subsequent in vitro assay $\left(\mathrm{IC}_{50}=\right.$ $0.07 \mathrm{mg} / \mathrm{ml}$ ), their results also revealed that NWT-03 could be able to inhibit DPP4 $\left(\mathrm{IC}_{50}=0.9 \mathrm{mg} / \mathrm{ml}\right)$. With this dual acting peptide, the authors wanted to address the question whether it could also beneficially affect T2DM developed parameters of renovascular damage. For that purpose, renal damage and vascular dysfunction was reviewed in an animal study in Zucker diabetic fatty (ZDF) rats, where NWT-03 was supplemented in drinking water $(1 \mathrm{~g} / \mathrm{kg} /$ day $)$ over a period of 15 weeks. The results were compared to a parallel ZDF rat group who were treated with the DPP4-Inhibitor vildagliptin (15 weeks, orally in drinking water, $3 \mathrm{mg} / \mathrm{kg} /$ day), which functions as a positive control for the effect of DDP4 inhibition. With this rat model, the authors showed that NWT-03 attenuates the development of renal damage. Furthermore, it has a preventing effect on aortic endothelial dysfuntion. The peptide is able to reduce albuminuria and focal glomerulosclerosis (FGS) by about $50 \%$ and moreover, is able to improve impaired endothelium dependent relaxation (EDR) response to acetylcholine $(\mathrm{AcH})$. The results of the vildagliptin treated control-group showed that this selective inhibitor has a positive effect on cytokines related to inflammation and glomerulosclerosis, but these effects are weaker when compared to NWT-03. Because of this, the authors concluded 


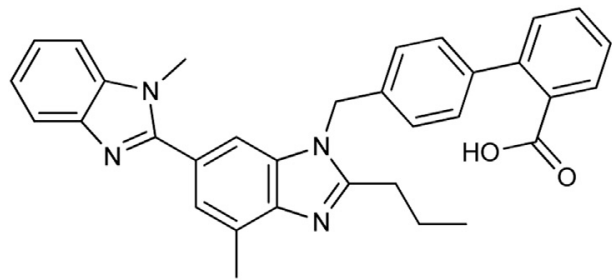

12 (Telmisartan) AT1 IC $50: 0.49 \mathrm{nM}$ PPARg EC 50 : 1520 nM (max. 33\%)<smiles>CCc1nc2c(C)cn(CC3=C(C#N)C=CCC3)c(=O)c2n1[C@H]1CCc2cc(-c3ccccc3-c3nnn[nH]3)ccc21</smiles>

14 AT1 IC ${ }_{50}: 7 \mathrm{nM}$ PPARg EC ${ }_{50}: 295 \mathrm{nM}(\max .27 \%)$

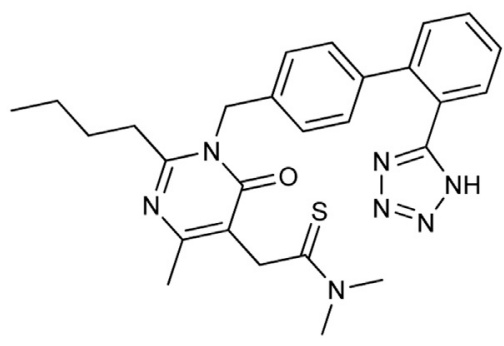

16 (Fimsartan) AT1 $\mathrm{IC}_{50}: 1.5 \mathrm{nM}$ PPARg $\mathrm{EC}_{50}: 460 \mathrm{nM}(\max .33 \%)$<smiles>CCc1nc2c(C)cc(CC(C)C)nc2n1[C@H]1CCc2cc(-c3ccccc3-c3nnn[nH]3)ccc21</smiles>

13

AT1 IC $50: 1.6 \mathrm{nM}$

PPARg EC 50 : 212 nM (max. 31\%)<smiles>CCCCn1c(-c2ccc3nn(CCC)c(Cc4ccc(-c5ccccc5-c5nnn[nH]5)cc4)c3c2)nc2ccccc21</smiles>

15

AT1 $\mathrm{IC}_{50}: 6 \mathrm{nM}$

PPARg EC E0 $_{50} 250$ nM (max. 40\%)<smiles>CCCCc1nc(C(C)C)c(CC(=S)N2CCCC2)c(=O)n1Cc1ccc(-c2ccccc2-c2noc(=O)[nH]2)cc1</smiles>

17

AT1 IC $50: 2.2 \mathrm{nM}$

PPARg EC 50 : $3.1 \mathrm{nM}$ (max. 66\%)

FIGURE 6 | Telmisartan and designed dual PPAR $\gamma / A T 1$ ligands.

that the more favorable effects of NWT-03 over vildagliptin are due to its ability to act dual on ACE and DPP4 (Wang et al., 2012).

In 2017 Sattigeri et al. presented the first approach toward a small molecule-based dual ACE/DPP4 inhibitor for the treatment of MetS (Figure 5) (Sattigeri et al., 2017). By analyzing ligand cocrystal structures of the DDP4-inhibitor sitagliptin (9) and the ACE inhibitor enalaprilat (10), critical potency-relevant interactions for both enzymes were identified. As a result of this approach the authors successfully merged the most relevant functional groups of enalaprilat, the active metabolite of enalapril and sitagliptin, together and received a new lead structure 11. Four derivatives with different terminal alkyl-residues were successfully characterized via molecular docking. The new ligands fit into the binding pockets very well and shows similar binding modes/molecular interactions compared to those already reported in literature. In vitro characterization of the molecules was performed in rat- (Wistar), mouse- (ob/ob) and human-plasma as an enzyme source. The results showed clearly that all compounds $\mathbf{1 1}$ are able to inhibit both enzymes, especially in human subjects with good potency, but the compounds also partially showed a very large inter-species shift. Nearly all compounds showed an excellent selectivity profiles against DASH- (dipeptidyl peptidase-IV activity and/ or structure homologues)-enzymes (DPP2, DPP8, DPP9) and non-DASH-enzymes (post-proline cleaving enzyme (PPCE), neutral endopeptidase (NEP), aminopeptidase $\mathrm{P}$ (APP) and aminopeptidase $\mathrm{N}$ (APN). Furthermore, the compounds 11 were stable in rat, mouse, dog and human liver microsomes. The plasma exposure profiles (Wistar rats following oral dosing, $30 \mathrm{mpk}$ ) are partially good. Overall the authors have successfully presented the first approaches toward a dual ACE/DPP4inhibitor which exhibits good and balanced potency on both targets and an advantageous in vitro profiles (Sattigeri et al., 2017).

\section{PPAR $\gamma$ and AT1}

The discovery of dual PPAR $\gamma$ agonists which additionally antagonize AT1 receptors can be considered as a design-in 
<smiles>CCCCCN(C(=O)Nc1nccs1)c1ccc(OC(C)(C)C(=O)O)cc1</smiles>

18 PPARg activation: >100\%max @ $10 \mu \mathrm{M}$<smiles>CCOC(=O)c1ccc(NC(=O)Cc2ccc(/C=C3\SC(=O)NC3=O)cc2[N+](=O)[O-])nc1</smiles>

20

GK activation: 2.7 fold @ $10 \mu \mathrm{M}$

PPARg activation: 48\%@10 $10 \mathrm{M}$

FIGURE 7 | Dual PPAR $\gamma /$ GK modulators.

approach. AT1 receptors are expressed in various tissues, most importantly kidney, heart, lung, and vessel walls (Kakar et al., 1992; Gasc et al., 1994). AT1 receptor responses to the binding of Angiotensin II and its activation leads to vasoconstriction, increased sodium reabsorption, and aldosterone levels (Schmieder, 2005). Selective antagonists of the AT1 receptor are also referred to as sartans. The pharmacological properties of AT1 receptor antagonists have been excessively reviewed previously (Timmermans, 1999). Since the discovery of first approved non-peptidic AT1 receptor antagonist losartan (Duncia et al., 1990), various sartans have been approved as first-line therapy for treatment of hypertension (Naik et al., 2010).

The first dual PPAR $\gamma / \mathrm{AT} 1$ receptor ligand is telmisartan (12, Figure 6), an antihypertensive drug discovered by Boehringer Ingelheim (Ries et al., 1993). Initially, telmisartan was considered to be a selective antihypertensive drug exhibiting sub-nanomolar $\mathrm{IC}_{50}$ value toward the AT1 receptor. Benson et al. discovered PPAR $\gamma$ modulating activity of telmisartan (Benson et al., 2004). Various clinical trials were performed to translate and confirm the beneficial effects of telmisartan compared to other AT1 receptor antagonists on glucose and lipid metabolism, however, these results were inconsistent (Derosa et al., 2004; Vitale et al., 2005; Hamada et al., 2014; Naruse et al., 2019). Metaanalysis of randomized controlled trials confirmed superiority of telmisartan in improvement of insulin resistance, reduction of fasting blood glucose and blood insulin levels (Wang et al., 2018). Telmisartan modulates PPAR $\gamma$ at low micromolar concentrations, the difference in effective concentration for pharmacodynamic modulation of PPAR $\gamma$ and AT1 receptor is quite high. Therefore, research has been conducted to design-in more potent modulation of PPAR $\gamma$ while preserving AT1 receptor antagonistic activity of telmisartan.

Casimiro-Garcia et al. presented two series of compounds which were derived from the telmisartan, developed at Pfizer (Casimiro-Garcia et al., 2011; Casimiro-Garcia et al., 2013). The lead compound for optimization was identified by screening AT1 receptor antagonists from previous lead optimization campaign. Subsequent multidimensional optimization led to identification of compound 13. 13 antagonized AT1 receptor with an $\mathrm{IC}_{50}$ of $1.6 \mathrm{nM}$ and modulated PPAR $\gamma$ activity with an $\mathrm{EC}_{50}$ of $212 \mathrm{nM}$ (Casimiro-Garcia et al., 2011). Similar results were obtained with compound 14 which exhibits a similar scaffold (Casimiro-Garcia et al., 2013). Very good pharmacokinetic profile allowed for testing in two distinct animal models. 14 effectively demonstrated pronounced and dose-dependent blood pressure lowering in spontaneously hypertensive rats (SHR). At the same time $\mathbf{1 4}$ lowered the blood glucose levels in male ZDF rats, which was far more pronounced compared to telmisartan (CasimiroGarcia et al., 2011). 
Lamotte et al. optimized the PPAR $\gamma$ modulation by switching the benzimidazole central core to indole, pyrazolopyridine, and indazole. The most promising indazole compound 15 exhibited an $\mathrm{IC}_{50}$ of $6 \mathrm{nM}$ toward AT1 receptor and modulated PPAR $\gamma$ activity with an $\mathrm{EC}_{50}$ of $250 \mathrm{nM}$. Very good exposure and bioavailability in rats allowed for testing in SHR where 15 significantly lowered systolic and diastolic blood pressure. In Zucker $f a / f a$ rats, 15 reduced the plasma insulin and plasma triglycerides. Interestingly, no body weight gain, a typical side effect of PPAR $\gamma$ full agonists, was observed in comparison to vehicle control (Lamotte et al., 2014).

In a more recent study by Choung et al., fimasartan (16) (Kim et al., 2012), an AT1 receptor antagonist approved in South Korea, was used as a starting point for optimization of PPAR $\gamma$ modulatory activity (Choung et al., 2018). The resulting dual modulator 17 reached higher activation efficacy compared to the lead structure and exhibited antihypertensive activity in vivo.

\section{PPAR $\gamma$ and GK}

Aside from the combination of an antihypertensive and antidiabetic activity in a designed multitarget ligand (DML), enhancement of antidiabetic activity by means of addressing two targets seems to be a valuable strategy. An example of a rational strategy to a synergistic antihyperglycaemic DMLs is the combined activation of PPAR $\gamma$ and Glucokinase (GK). GK catalyzes the phosphorylation of glucose. The product of GK-catalyzed reaction, Glucose-6-phospate, can subsequently enter the glycolysis or being incorporated into glycogen. Thus, activation of GK efficiently promotes the storage of glucose from blood in hepatocytes. Furthermore, GK acts as a glucose sensor in pancreatic islet cells and promotes insulin secretion (Toulis et al., 2020). A DML which is able to activate GK and PPAR $\gamma$ simultaneously has the potential to synergistically decrease the glucose levels, promote insulin secretion and sensitize muscle cells to insulin response.

Lu et al. coupled diverse GK activator pharmacophores into thiazolidinediones which are well-known as $\operatorname{PPAR} \gamma$ agonists. Although several compounds, including 20, were shown to exhibit dual activity of both, GK and PPAR $\gamma$, further evaluation is not reported (Lu et al., 2014). Li et al. linked a benzthiazole- and thiazole-2-urea moiety, which is described as a pharmacophore for potent GK activation to a fibrate pharmacophore (Figure 7). The subsequent investigation of the length of the tertiary urea alkyl substituent and substitution patterns of the heterocycle led to discovery of 18. Compound 18 activated GK and PPAR $\gamma$ in low micromolar range. However, the in vivo glucose lowering effects observed during the fasting blood glucose tests in ICR mice upon exposure were very moderate which was caused by very rapid clearance of $\mathbf{1 8}$ from the blood (Li et al., 2014).

Compound 19 (SHP289-03) was found by screening for dual GK/PPAR $\gamma$ activators and is a derivative of the GK activator GKA 22 discovered by AstraZeneca. It partially activates PPAR $\gamma$ and exhibits 1.7 fold activation of GK at $50 \mu \mathrm{M}$. Interestingly, 19 acts as a partial PPAR $\gamma$ agonist and does not promote adipocyte differentiation while it leads to mRNA increase of PPAR $\gamma$ dependent gene Adrp and aP2. In contrast to compound 18, compound 19 (SHP289-03) exhibits much better pharmacokinetic properties in rats. In type 2 diabetic $\mathrm{KKA}^{\mathrm{y}}$ mice, 19 leads to a pronounced and dose-dependent improvement of hyperglycemia and insulin secretion. Surprisingly, lipid parameters and body weight were improved in animals treated with 19 for 25 days at doses of $25 \mathrm{mg} / \mathrm{kg}$ and $50 \mathrm{mg} / \mathrm{kg}$, demonstrating the potential of dual GK/PPAR $\gamma$ activators as drugs for treatment of MetS (Lei et al., 2015).

\section{DPP4 and GPR119}

As described above, treatment with DPP4 inhibitors leads to an increase of GLP-1 in plasma and subsequent secretion of insulin in response to elevated blood glucose levels. An increased glucose-dependent insulin secretion in pancreatic $\beta$-cells as well as an increased release of GLP-1 in intestinal L-cells can also be achieved by the activation of GPR119 (Yang et al., 2018), a G-protein coupled receptor $(\mathrm{GP}(\mathrm{C}) \mathrm{R})$, which is mainly expressed in the small intestine and in the pancreas (Odori et al., 2013). Therefore, GPR119 agonists could improve glucose homeostasis in patients with T2DM. The search for endogenous ligands of GPR119 yielded two main classes, amide derivatives of fatty acids, such as oleoylethanolamides (OEA), and phospholipids, such as oleyollysophosphatidylcholine (Hansen et al., 2012). In addition, a large number of synthetic compounds have already been identified which can activate GPR119 effectively and selectively (Ritter et al., 2016). Preclinical and clinical studies with various compounds have shown the potential for the treatment of T2DM, but there is still a long way to go before a candidate is approved. Due to the complementary mechanisms of action of DPP4 inhibitors and GPR119 agonists, numerous studies investigated and confirmed the synergistic effect of this target combination (Ansarullah et al., 2013).

The first dual DPP4/GPR119 modulator was introduced in 2016 by $\mathrm{Li}$ et al. (2016) They analyzed the most important pharmacophore properties of the DPP4 inhibitor linagliptin (xanthine scaffold) and the three GPR119 agonists AR231453, APD597, and PSN632408 (4-piperidine moiety) and developed a lead structure in a pharmacophore merging approach. A systematic optimization led to compound 21. This dual modulator is able to activate GPR119 $\left(\mathrm{EC}_{50}: 0.95 \mu \mathrm{M}, 81.5 \%\right.$ activity of AR231453 $@ 1 \mu \mathrm{M})$ and inhibit DPP4 ( $\left.\mathrm{IC}_{50}: 0.22 \mu \mathrm{M}\right)$ in vitro. 21 also exhibits favorable selectivity against DPP8/9 (36.8\% inhibition $@ 10 \mu \mathrm{M})$ as well as an acceptable in vitro pharmacological profile.

Optimization of $\mathbf{2 1}$ by Huan et al. led to compound 22 (Huan et al., 2017). 22 is able to inhibit DPP4 ex vivo $\left(\mathrm{IC}_{50}: 0.066 \mu \mathrm{M}\right)$ as well as in vivo (ICR mice, $30 \mathrm{mg} / \mathrm{kg}, 50 \%$ DPP4 inhibition for about $4 \mathrm{~h}$ ) and maintains selectivity against DPP8/9. GPR119 is activated in vitro by $22\left(\mathrm{EC}_{50}: 0.03 \mu \mathrm{M}, 73.6 \%\right.$ activity of APD597 $@ 10 \mu \mathrm{M})$. It is also selective via other GPCRs such as GPR40, GLP1R and GIPR. Further ex and in vivo experiments support the authors' statement that the dual DPP4/GPR119 modulator 22 could be a very promising candidate for the treatment of T2DM. In 2020 the same group published the SAR that led to the identification of $\mathbf{2 2}$ (Li et al., 2020). An improvement was acchived by using the hydrochloride salt of $\mathbf{2 2}$ which displays an improved bioavailability and blood sugar lowering effect in ICR mice as well as a favorable PK/PD. A mini-AMES test was negative and also the preliminary acute toxicity in mice shows an $\mathrm{LD}_{50}$ of more than $1.5 \mathrm{~g} / \mathrm{kg}$ in first tests. The moderate inhibition of the hERG channel $\left(\mathrm{IC}_{50}: 4.9 \mu \mathrm{M}\right)$, which according to the 
authors' hypothesis is due to the high lipophilicity of the compound, represents a challenge to be solved in the future.

In 2020, Fang et al. presented another dual modulator, the tetrahydropyrimidine derivative $\mathbf{2 3}$ (Fang et al., 2020). Based on the previously developed GPR119 agonists (Fang et al., 2019), the dual modulator was designed via pharmacophore combination and scaffold hopping. A central tetrahydropyrimidine nucleus was combined with a substituted aniline and seven different DPP4 inhibitors from literature, which led to the identification of 23. The compound displays inhibitory activity against DPP4 $(74.5 \% @ 10 \mu \mathrm{M})$ and is also a highly potent GPR119 agonist $\left(\mathrm{EC}_{50}: 0.0087 \mu \mathrm{M}\right.$, in a cell-based cAMP assay, $85.4 \% \max$; compared to max. effect of GSK1292263). The calculated clogP of 2.1 indicates a suitable lipophilicity. In an oral glucose tolerance test in $\mathrm{C} 57 \mathrm{BL} / 6 \mathrm{~N}$ mice $\mathbf{2 3}$ also showed a stronger hypoglycemic effect than the DPP4 inhibitor vildagliptin.

\section{DPP4 and MCH-1R}

As already mentioned, obesity is one of the central risk factors of MetS. One of the many approaches to treat obesity is appetite control (Sargent and Moore, 2009). A receptor that could play an important role in this context in the future is the melanin concentrating hormone receptor 1 (MCH-1R/ GPR24/ SLC-1). This GPCR is activated by the melanin-concentrating hormone $(\mathrm{MCH})$, a cyclic neuropeptide with 19 amino acids, which is synthesized in mammals primarily by neurons in the lateral hypothalamus $(\mathrm{LH})$ and the zona incerta of the subthalamus. The important role $\mathrm{MCH}$ has with regards to food intake and energy balance has been investigated and confirmed in numerous animal studies (Luthin, 2007; Mihalic et al., 2011). In addition to $\mathrm{MCH}-1 \mathrm{R}$, there is also a second $\mathrm{MCH}$ receptor, $\mathrm{MCH}-2 \mathrm{R}$, whose physiological role in humans has not been elucidated yet (Omran, 2017). A number of MCH-1R antagonists have already been described in the literature (Johansson and Löfberg, 2015) and it could be shown early on that they suppress $\mathrm{MCH}$-induced food intake and thus lead to a reduction in weight gain (Borowsky et al., 2002; Takekawa et al., 2002). A problem in the development of this compound class is the correlation of the structural as well as physico-chemical requirements for MCH-1R potency and hERG channel inhibition resulting in an increased cardiovascular risk (Högberg et al., 2012). Up to now, only a few candidates were investigated in clinical trials. For various reasons, however, in no case has phase 1 been exceeded and the concept of weight loss mediated by $\mathrm{MCH}-1 \mathrm{R}$ inhibition has thus not been confirmed in humans yet (Omran, 2017). Although the development of selective $\mathrm{MCH}-1 \mathrm{R}$ antagonists is associated with a number of challenges, the combination with a DPP4 inhibitor could be an attractive combination resulting in an oral anti-diabetic agent which would also contribute to reduction of body weight.

Gattrell et al. presented the first approach to the development of a dual DPP4/MCH-1R modulator (Gattrell et al., 2012). Based on ligand data from the chemical literature and patents they identified molecules that share a common structural motif and developed a lead structure. Subsequently, they identified further $\mathrm{MCH}-1 \mathrm{R}$ ligands with a similar binding mode via molecular docking, fragmented them and filtered them according to predetermined physicochemical properties. The resulting initial set of analogues was tested and, after further minor modifications, compound 24 was obtained. Analysis of the $\mathrm{MCH}-1 \mathrm{R}$ antagonism $\left(\mathrm{IC}_{50}: 0.44 \mu \mathrm{M}\right)$ and $\mathrm{DPP} 4$ inhibition $\left(\mathrm{IC}_{50}: 0.35 \mu \mathrm{M}\right)$ showed that 24 is almost equipotent on both targets and also selective against DDP8/9. The hERG inhibition data of two analogues of $\mathbf{2 4}$ also suggest that the presented chemotype is a good starting point for further lead structure optimization.

\section{CONCLUSION}

In conclusion, the summarized studies indicate the potential of facing a multifactorial disease by combining two selective inhibitors into one molecule with dual modulator activity. There are multiple reasons for introducing multi-target activity in compounds for treatment of MetS (Table 1). First, avoidance of polypharmaceutical treatment can be potentially achieved by combining anti-hypertensional and antidiabetic activity as it was shown for AT1/PPAR $\gamma, \operatorname{sEH} / \operatorname{PPAR} \gamma$, or $\mathrm{ACE} / \mathrm{DPP} 4$ ligands. The in vivo evaluation of most advanced compounds demonstrates great potential in efficacy; however, clinical trials are lacking. Second, enhancement of efficacy against particular MetS associated morbidities can be achieved by combining targets such as sEH/FXR or GK/PPAR $\gamma$. This approach also holds great potential to reduce polypharmacological treatment due to the fact that these diseases are managed with multiple drugs at the moment. Medicinal chemistry demonstrated the capability to deliver potent multitarget modulators with favorable pharmacokinetic properties. Furthermore, innovative animal models of MetS are able to reflect the whole spectrum of symptoms, thereby are able to reflect the whole spectrum of symptoms such that the full potential of multitarget ligands can be evaluated. A future perspective for these compounds should be evaluated in clinical trials to demonstrate the full potential of multitarget drugs in patients.

\section{AUTHOR CONTRIBUTIONS}

All authors listed have made a substantial, direct, and intellectual contribution to the work and approved it for publication.

\section{FUNDING}

EP was supported by the German Research Foundation (DFG, Heisenberg-Professur PR1405/7-1 and SFB 1039 TP A07). JI was supported by a National Institute of Health (NIH) grant (DK103616) and Ralph and Marian Falk Medical Research Trust Bank of America, N.A., Trustee grant.

\section{ACKNOWLEDGMENTS}

Servier Medical Art was used to generate Figure $\mathbf{1}$ and is licensed by Servier under a Creative Commons Attribution 3.0 Unported License. 


\section{REFERENCES}

Alberti, K. G. M. M., Zimmet, P., and Shaw, J. IDF Epidemiology Task Force Consensus Group (2005). The metabolic syndrome--a new worldwide definition. Lancet 366, 1059-1062. doi:10.1016/S0140-6736(05)67402-8

Ali, A. H., Carey, E. J., and Lindor, K. D. (2015). Recent advances in the development of farnesoid X receptor agonists. Ann. Transl. Med. 3, 5. doi:10.3978/j.issn.2305-5839.2014.12.06

Alwhaibi, M., Balkhi, B., Alhawassi, T. M., Alkofide, H., Alduhaim, N., Alabdulali, R., et al. (2018). Polypharmacy among patients with diabetes: a cross-sectional retrospective study in a tertiary hospital in saudi arabia. BMJ Open 8, e020852. doi:10.1136/bmjopen-2017-020852

Ammazzalorso, A., Maccallini, C., Amoia, P., and Amoroso, R. (2019). Multitarget PPAR $\gamma$ agonists as innovative modulators of the metabolic syndrome. Eur. J. Med. Chem. 173, 261-273. doi:10.1016/j.ejmech.2019.04.030

AnsarullahLu, Y., Holstein, M., DeRuyter, B., Rabinovitch, A., and Guo, Z. (2013). Stimulating $\beta$-cell regeneration by combining a GPR119 agonist with a DPP-IV inhibitor. PLoS One 8, e53345. doi:10.1371/journal.pone.0053345

Basaranoglu, M., and Neuschwander-Tetri, B. A. (2006). Nonalcoholic fatty liver disease: clinical features and pathogenesis. Gastroenterol. Hepatol. 2, 282-291.

Benson, S. C., Pershadsingh, H. A., Ho, C. I., Chittiboyina, A., Desai, P., Pravenec, M., et al. (2004). Identification of telmisartan as a unique angiotensin II receptor antagonist with selective PPARgamma-modulating activity. Hypertension 43, 993-1002. doi:10.1161/01.HYP.0000123072.34629.57

Bernardi, S., Marcuzzi, A., Piscianz, E., Tommasini, A., and Fabris, B. (2018). The complex interplay between lipids, immune system and interleukins in cardiometabolic diseases. Int. J. Mol. Sci. 19, 4058. doi:10.3390/ijms19124058

Bianchi, C., Penno, G., Romero, F., Del Prato, S., and Miccoli, R. (2007). Treating the metabolic syndrome. Expet Rev. Cardiovasc. Ther. 5, 491-506. doi:10.1586/ 14779072.5.3.491

Blöcher, R., Lamers, C., Wittmann, S. K., Merk, D., Hartmann, M., Weizel, L., et al. (2016). N-benzylbenzamides: a novel merged scaffold for orally available dual soluble epoxide hydrolase/peroxisome proliferator-activated receptor $\gamma$ modulators. J. Med. Chem. 59, 61-81. doi:10.1021/acs.jmedchem.5b01239

Borowsky, B., Durkin, M. M., Ogozalek, K., Marzabadi, M. R., DeLeon, J., Lagu, B., et al. (2002). Antidepressant, anxiolytic and anorectic effects of a melaninconcentrating hormone-1 receptor antagonist. Nat. Med. 8, 825-830. doi:10. $1038 / \mathrm{nm} 741$

Campbell, W. B., Imig, J. D., Schmitz, J. M., and Falck, J. R. (2017). Orally active epoxyeicosatrienoic acid analogs. J. Cardiovasc. Pharmacol. 70, 211-224. doi:10. 1097/FJC.0000000000000523

Cariou, B., and Staels, B. (2007). FXR: a promising target for the metabolic syndrome?. Trends Pharmacol. Sci. 28, 236-243. doi:10.1016/j.tips.2007.03.002

Carr, R. M., and Reid, A. E. (2015). FXR agonists as therapeutic agents for nonalcoholic fatty liver disease. Curr. Atherosclerosis Rep. 17, 500. doi:10.1007/ s11883-015-0500-2

Casimiro-Garcia, A., Filzen, G. F., Flynn, D., Bigge, C. F., Chen, J., Davis, J. A., et al. (2011). Discovery of a series of imidazo[4,5-b]pyridines with dual activity at angiotensin II type 1 receptor and peroxisome proliferator-activated receptor- $\gamma$. J. Med. Chem. 54, 4219-4233. doi:10.1021/jm200409s

Casimiro-Garcia, A., Heemstra, R. J., Bigge, C. F., Chen, J., Ciske, F. A., Davis, J. A., et al. (2013). Design, synthesis, and evaluation of imidazo[4,5-c]pyridin-4-one derivatives with dual activity at angiotensin II type 1 receptor and peroxisome proliferator-activated receptor- $\gamma$. Bioorg. Med. Chem. Lett. 23, 767-772. doi:10. 1016/j.bmcl.2012.11.088

Cave, M. C., Clair, H. B., Hardesty, J. E., Falkner, K. C., Feng, W., Clark, B. J., et al. (2016). Nuclear receptors and nonalcoholic fatty liver disease. Biochim. Biophys. Acta. 1859, 1083-1099. doi:10.1016/j.bbagrm.2016.03.002

Chalasani, N., Younossi, Z., Lavine, J. E., Diehl, A. M., Brunt, E. M., Cusi, K., et al. (2012). The diagnosis and management of non-alcoholic fatty liver disease: practice guideline by the american association for the study of liver diseases, american college of gastroenterology, and the american gastroenterological association. Hepatology 55, 2005-2023. doi:10.1002/hep.25762

Charbonnel, B., Karasik, A., Liu, J., Wu, M., and Meininger, G. Sitagliptin Study 020 Group (2006). Efficacy and safety of the dipeptidyl peptidase-4 inhibitor sitagliptin added to ongoing metformin therapy in patients with type 2 diabetes inadequately controlled with metformin alone. Diabetes Care 29, 2638-2643. doi: $10.2337 / \mathrm{dc} 06-0706$
Chianelli, D., Rucker, P. V., Roland, J., Tully, D. C., Nelson, J., Liu, X., et al. (2020). Nidufexor (LMB763), a novel FXR modulator for the treatment of nonalcoholic steatohepatitis. J. Med. Chem. 63 (8), 3868-3880. doi:10.1021/acs.jmedchem. $9 \mathrm{~b} 01621$

Choung, W., Jung, H. J., Nam, E. H., Yang, D., Yoo, B., Choi, H., et al. (2018). Discovery of the bifunctional modulator of angiotensin II type 1 receptor (AT1R) and PPAR $\gamma$ derived from the AT1R antagonist, fimasartan. Bioorg. Med. Chem. Lett. 28, 3155-3160. doi:10.1016/j.bmcl.2018.08.036

Christensen, R., Kristensen, P. K., Bartels, E. M., Bliddal, H., and Astrup, A. (2007). Efficacy and safety of the weight-loss drug rimonabant: a meta-analysis of randomised trials. Lancet 370, 1706-1713. doi:10.1016/S0140-6736(07)61721-8

Dandona, P., Aljada, A., Chaudhuri, A., Mohanty, P., and Garg, R. (2005). Metabolic syndrome: a comprehensive perspective based on interactions between obesity, diabetes, and inflammation. Circulation 111, 1448-1454. doi:10.1161/01.CIR.0000158483.13093.9D

Derosa, G., Ragonesi, P. D., Mugellini, A., Ciccarelli, L., and Fogari, R. (2004) Effects of telmisartan compared with eprosartan on blood pressure control, glucose metabolism and lipid profile in hypertensive, type 2 diabetic patients: a randomized, double-blind, placebo-controlled 12-month study. Hypertens. Res. 27, 457-464. doi:10.1291/hypres.27.457

Després, J.-P., Van Gaal, L., Pi-Sunyer, X., and Scheen, A. (2008). Efficacy and safety of the weight-loss drug rimonabant. Lancet 371, 555-556. doi:10.1016/ S0140-6736(08)60261-5

Dhillon, S. (2018). Semaglutide: first global approval. Drugs 78, 275-284. doi:10. 1007/s40265-018-0871-0

Duncia, J. V., Chiu, A. T., Carini, D. J., Gregory, G. B., Johnson, A. L., Price, W. A., et al. (1990). The discovery of potent nonpeptide angiotensin II receptor antagonists: a new class of potent antihypertensives. J. Med. Chem. 33, 1312-1329. doi:10.1021/jm00167a007

Durinx, C., Lambeir, A. M., Bosmans, E., Falmagne, J. B., Berghmans, R., Haemers, A., et al. (2000). Molecular characterization of dipeptidyl peptidase activity in serum: soluble CD26/dipeptidyl peptidase IV is responsible for the release of X-Pro dipeptides. Eur. J. Biochem. 267, 5608-5613. doi:10.1046/j.1432-1327.2000.01634.x

Eckel, R. H., Grundy, S. M., and Zimmet, P. Z. (2005). The metabolic syndrome. Lancet 365, 1415-1428. doi:10.1016/S0140-6736(05)66378-7

El-Kader, S. M. A., and El-Den Ashmawy, E. M. S. (2015). Non-alcoholic fatty liver disease: the diagnosis and management. World J. Hepatol. 7, 846-858. doi:10. 4254/wjh.v7.i6.846

Ernsberger, P., Koletsky, R. J., and Friedman, J. E. (1999). Molecular pathology in the obese spontaneous hypertensive koletsky rat: a model of syndrome X. Ann. N. Y. Acad. Sci. 892, 272-288. doi:10.1111/j.1749-6632.1999.tb07801.x

Esser, N., Legrand-Poels, S., Piette, J., Scheen, A. J., and Paquot, N. (2014). Inflammation as a link between obesity, metabolic syndrome and type 2 diabetes. Diabetes Res. Clin. Pract. 105, 141-150. doi:10.1016/j.diabres.2014.04.006

Evans, R. M., Barish, G. D., and Wang, Y.-X. (2004). PPARs and the complex journey to obesity. Nat. Med. 10, 355-361. doi:10.1038/nm1025

Fang, Y., Xiong, L., Hu, J., Zhang, S., Xie, S., Tu, L., et al. (2019). Synthesis and evaluation of novel fused pyrimidine derivatives as GPR119 agonists. Bioorg. Chem. 86, 103-111. doi:10.1016/j.bioorg.2019.01.032

Fang, Y., Zhang, S., Wu, W., Liu, Y., Yang, J., Li, Y., et al. (2020). Design and synthesis of tetrahydropyridopyrimidine derivatives as dual GPR119 and DPP4 modulators. Bioorg. Chem. 94, 103390. doi:10.1016/j.bioorg.2019.103390

Feng, Y., Huang, R., Kavanagh, J., Li, L., Zeng, X., Li, Y., et al. (2019). Efficacy and safety of dual blockade of the renin-angiotensin-aldosterone system in diabetic kidney disease: a meta-analysis. Am. J. Cardiovasc. Drugs 19, 259-286. doi:10. 1007/s40256-018-00321-5

Ferrario, C. M., and Strawn, W. B. (2006). Role of the renin-angiotensinaldosterone system and proinflammatory mediators in cardiovascular disease. Am. J. Cardiol. 98, 121-128. doi:10.1016/j.amjcard.2006.01.059

Fiorucci, S., Rizzo, G., Antonelli, E., Renga, B., Mencarelli, A., Riccardi, L., et al. (2005). Cross-talk between farnesoid-X-receptor (FXR) and peroxisome proliferator-activated receptor gamma contributes to the antifibrotic activity of FXR ligands in rodent models of liver cirrhosis. J. Pharmacol. Exp. Ther. 315, 58-68. doi:10.1124/jpet.105.085597

Forbes, J. M., and Cooper, M. E. (2013). Mechanisms of diabetic complications. Physiol. Rev. 93, 137-188. doi:10.1152/physrev.00045.2011

Gasc, J. M., Shanmugam, S., Sibony, M., and Corvol, P. (1994). Tissue-specific expression of type 1 angiotensin II receptor subtypes. An in situ hybridization study. Hypertension 24, 531-537. doi:10.1161/01.hyp.24.5.531 
Gattrell, W. T., Sambrook Smith, C. P., and Smith, A. J. (2012). An example of designed multiple ligands spanning protein classes: dual MCH-1R antagonists/ DPPIV inhibitors. Bioorg. Med. Chem. Lett. 22, 2464-2469. doi:10.1016/j.bmcl. 2012.02.010

Germain, P., Chambon, P., Eichele, G., Evans, R. M., Lazar, M. A., Leid, M., et al. (2006). International union of pharmacology. LXIII. Retinoid X receptors. Pharmacol. Rev. 58, 760-772. doi:10.1124/pr.58.4.7

Grant, R. W., Devita, N. G., Singer, D. E., and Meigs, J. B. (2003). Polypharmacy and medication adherence in patients with type 2 diabetes. Diabetes Care 26, 1408-1412. doi:10.2337/diacare.26.5.1408

Grigoropoulou, P., Eleftheriadou, I., Zoupas, C., Diamanti-Kandarakis, E., and Tentolouris, N. (2013). Incretin-based therapies for type 2 diabetes mellitus: effects on insulin resistance. Curr. Diabetes Rev. 9, 412-417. doi:10.2174/ 15733998113099990070

Grundy, S. M., Brewer, H. B., Cleeman, J. I., Smith, S. C., and Lenfant, C. (2004). American Heart Association, et al.Definition of metabolic syndrome: report of the National Heart, Lung, and Blood Institute/American Heart Association conference on scientific issues related to definition. Circulation 109, 433-438. doi:10.1161/01.CIR.0000111245.75752.C6

Grundy, S. M., Cleeman, J. I., Daniels, S. R., Donato, K. A., Eckel, R. H., Franklin, B. A., et al. (2005). Diagnosis and management of the metabolic syndrome: an American heart association/national heart, lung, and blood Institute scientific statement. Circulation 112, 2735-2752. doi:10.1161/CIRCULATIONAHA.105.169404

Grundy, S. M. (2006). Drug therapy of the metabolic syndrome: minimizing the emerging crisis in polypharmacy. Nat. Rev. Drug Discov. 5, 295-309. doi:10. 1038/nrd2005

Guan, Y., Hao, C., Cha, D. R., Rao, R., Lu, W., Kohan, D. E., et al. (2005). Thiazolidinediones expand body fluid volume through PPARgamma stimulation of ENaC-mediated renal salt absorption. Nat. Med. 11, 861-866. doi:10.1038/nm1278

Hamada, T., Kuwabara, M., Watanabe, A., Mizuta, E., Ohtahara, A., Omodani, H., et al. (2014). A comparative study on the effectiveness of losartan/hydrochlorothiazide and telmisartan/hydrochlorothiazide in patients with hypertension. Clin. Exp. Hypertens 36, 251-257. doi:10.3109/10641963.2013.810228

Han, C. Y. (2018). Update on FXR biology: promising therapeutic target?. Int. J. Mol. Sci. 19, 2069. doi:10.3390/ijms19072069

Handelsman, Y., and Jellinger, P. S. (2011). Overcoming obstacles in risk factor management in type 2 diabetes mellitus. J. Clin. Hypertens 13, 613-620. doi:10. $1111 / \mathrm{j} .1751-7176.2011 .00490 . x$

Hansen, H. S., Rosenkilde, M. M., Holst, J. J., and Schwartz, T. W. (2012). GPR119 as a fat sensor. Trends Pharmacol. Sci. 33, 374-381. doi:10.1016/j.tips.2012.03.014

Högberg, T., Frimurer, T. M., and Sasmal, P. K. (2012). Melanin concentrating hormone receptor 1 (MCHR1) antagonists-Still a viable approach for obesity treatment?. Bioorg. Med. Chem. Lett. 22, 6039-6047. doi:10.1016/j.bmcl.2012.08.025

Hotamisligil, G. S. (2006). Inflammation and metabolic disorders. Nature 444, 860-867. doi:10.1038/nature0548

Huan, Y., Jiang, Q., Li, G., Bai, G., Zhou, T., Liu, S., et al. (2017). The dual DPP4 inhibitor and GPR119 agonist HBK001 regulates glycemic control and beta cell function ex and in vivo. Sci. Rep. 7, 4351. doi:10.1038/s41598-017-04633-5

Hwang, S. H., Tsai, H.-J., Liu, J.-Y., Morisseau, C., and Hammock, B. D. (2007). Orally bioavailable potent soluble epoxide hydrolase inhibitors. J. Med. Chem. 50, 3825-3840. doi:10.1021/jm070270t

Hye Khan, M. A., Kolb, L., Skibba, M., Hartmann, M., Blöcher, R., Proschak, E., et al. (2018). A novel dual PPAR- $\gamma$ agonist/sEH inhibitor treats diabetic complications in a rat model of type 2 diabetes. Diabetologia 61, 2235-2246. doi:10.1007/s00125-018-4685-0

Hye Khan, M. A., Schmidt, J., Stavniichuk, A., Imig, J. D., and Merk, D. (2019). A dual farnesoid X receptor/soluble epoxide hydrolase modulator treats nonalcoholic steatohepatitis in mice. Biochem. Pharmacol. 166, 212-221. doi:10. 1016/j.bcp.2019.05.023

Imig, J. D., and Hammock, B. D. (2009). Soluble epoxide hydrolase as a therapeutic target for cardiovascular diseases. Nat. Rev. Drug Discov. 8, 794-805. doi:10. $1038 / \mathrm{nrd} 2875$

Imig, J. D., Walsh, K. A., Hye Khan, M. A., Nagasawa, T., Cherian-Shaw, M., Shaw, S. M., et al. (2012). Soluble epoxide hydrolase inhibition and peroxisome proliferator activated receptor $\gamma$ agonist improve vascular function and decrease renal injury in hypertensive obese rats. Exp. Biol. Med. 237, 1402-1412. doi:10.1258/ebm.2012.012225
Inagaki, T., Dutchak, P., Zhao, G., Ding, X., Gautron, L., Parameswara, V., et al. (2007). Endocrine regulation of the fasting response by PPARalpha-mediated induction of fibroblast growth factor 21. Cell Metabol. 5, 415-425. doi:10.1016/j. cmet.2007.05.003

Jain, M. R., Giri, S. R., Bhoi, B., Trivedi, C., Rath, A., Rathod, R., et al. (2018). Dual $\mathrm{PPAR} \alpha / \gamma$ agonist saroglitazar improves liver histopathology and biochemistry in experimental NASH models. Liver Int. 38, 1084-1094. doi:10.1111/liv.13634

Johansson, A., and Löfberg, C. (2015). Novel MCH1 receptor antagonists: a patent review. Expert Opin. Ther. Pat. 25, 193-207. doi:10.1517/13543776.2014. 993382

Kahn, R., Buse, J., Ferrannini, E., and Stern, M. (2005). The metabolic syndrome: time for a critical appraisal. joint statement from the american diabetes association and the european association for the study of diabetes. Diabetologia 48, 1684-1699. doi:10.1007/s00125-005-1876-2

Kakar, S. S., Sellers, J. C., Devor, D. C., Musgrove, L. C., and Neill, J. D. (1992). Angiotensin II type-1 receptor subtype cDNAs: differential tissue expression and hormonal regulation. Biochem. Biophys. Res. Commun. 183, 1090-1096. doi:10.1016/s0006-291x(05)80302-x

Kersten, S. (2014). Integrated physiology and systems biology of PPARa. Mol. Metab. 3, 354-371. doi:10.1016/j.molmet.2014.02.002

Kim, T. W., Yoo, B. W., Lee, J. K., Kim, J. H., Lee, K.-T., Chi, Y. H., et al. (2012). Synthesis and antihypertensive activity of pyrimidin- $4(3 \mathrm{H})$-one derivatives as losartan analogue for new angiotensin II receptor type 1 (AT1) antagonists. Bioorg. Med. Chem. Lett. 22, 1649-1654. doi:10.1016/j.bmcl.2011.12.116

Kompa, A. R., Wang, B. H., Xu, G., Zhang, Y., Ho, P.-Y., Eisennagel, S., et al. (2013). Soluble epoxide hydrolase inhibition exerts beneficial anti-remodeling actions post-myocardial infarction. Int. J. Cardiol. 167, 210-219. doi:10.1016/j.ijcard. 2011.12.062

Kramer, J., and Proschak, E. (2017). Phosphatase activity of soluble epoxide hydrolase. Prostag. Other Lipid Mediat. 133, 88-92. doi:10.1016/j.prostaglandins.2017.07.002

la Buscató, E., Blöcher, R., Lamers, C., Klingler, F.-M., Hahn, S., Steinhilber, D., et al. (2012). Design and synthesis of dual modulators of soluble epoxide hydrolase and peroxisome proliferator-activated receptors. J. Med. Chem. 55, 10771-10775. doi:10.1021/jm301194c

Lamotte, Y., Faucher, N., Sançon, J., Pineau, O., Sautet, S., Fouchet, M.-H., et al. (2014). Discovery of novel indazole derivatives as dual angiotensin II antagonists and partial PPAR $\gamma$ agonists. Bioorg. Med. Chem. Lett. 24, 1098-1103. doi:10.1016/j.bmcl.2014.01.004

Lee, J. M. (2016). Transcriptional coordination of hepatic autophagy by nutrientsensing nuclear receptor PPARa and FXR. Ann. Pediatr. Endocrinol. Metab. 21, 193-198. doi:10.6065/apem.2016.21.4.193

Lei, L., Liu, Q., Liu, S., Huan, Y., Sun, S., Chen, Z., et al. (2015). Antidiabetic potential of a novel dual-target activator of glucokinase and peroxisome proliferator activated receptor- $\gamma$. Metab. Clin. Exp. 64, 1250-1261. doi:10. 1016/j.metabol.2015.06.014

Li, G., Huan, Y., Yuan, B., Wang, J., Jiang, Q., Lin, Z., et al. (2016). Discovery of novel xanthine compounds targeting DPP-IV and GPR119 as anti-diabetic agents. Eur. J. Med. Chem. 124, 103-116. doi:10.1016/j.ejmech.2016.08.023

Li, G., Meng, B., Yuan, B., Huan, Y., Zhou, T., Jiang, Q., et al. (2020). The optimization of xanthine derivatives leading to HBK001 hydrochloride as a potent dual ligand targeting DPP-IV and GPR119. Eur. J. Med. Chem. 188, 112017. doi:10.1016/j.ejmech.2019.112017

Li, Y., Tian, K., Qin, A., Zhang, L., Huo, L., Lei, L., et al. (2014). Discovery of novel urea derivatives as dual-target hypoglycemic agents that activate glucokinase and PPAR $\gamma$. Eur. J. Med. Chem. 76, 182-192. doi:10.1016/j.ejmech.2014.02.024

Liu, Y., Dang, H., Li, D., Pang, W., Hammock, B. D., and Zhu, Y. (2012). Inhibition of soluble epoxide hydrolase attenuates high-fat-diet-induced hepatic steatosis by reduced systemic inflammatory status in mice. PLoS One 7, e39165. doi:10. 1371/journal.pone.0039165

Liu, Y., Zhang, Y., Schmelzer, K., Lee, T.-S., Fang, X., Zhu, Y., et al. (2005). The antiinflammatory effect of laminar flow: the role of PPARgamma, epoxyeicosatrienoic acids, and soluble epoxide hydrolase. Proc. Natl. Acad. Sci. U.S.A. 102, 16747-16752. doi:10.1073/pnas.0508081102

Lu, J., Lei, L., Huan, Y., Li, Y., Zhang, L., Shen, Z., et al. (2014). Design, synthesis, and activity evaluation of GK/PPAR $\gamma$ dual-target-directed ligands as hypoglycemic agents. Chem. Med. Chem. 9, 922-927. doi:10.1002/cmdc.201400009

Luthin, D. R. (2007). Anti-obesity effects of small molecule melanin-concentrating hormone receptor 1 (MCHR1) antagonists. Life Sci. 81, 423-440. doi:10.1016/j.lfs.2007.05.029 
Ma, H., and Patti, M. E. (2014). Bile acids, obesity, and the metabolic syndrome. Best Pract. Res. Clin. Gastroenterol. 28, 573-583. doi:10.1016/j.bpg.2014.07.004

Makishima, M., Okamoto, A. Y., Repa, J. J., Tu, H., Learned, R. M., Luk, A., et al. (1999). Identification of a nuclear receptor for bile acids. Science 284, 1362-1365. doi:10.1126/science.284.5418.1362

Maloney, P. R., Parks, D. J., Haffner, C. D., Fivush, A. M., Chandra, G., Plunket, K. D., et al. (2000). Identification of a chemical tool for the orphan nuclear receptor FXR. J. Med. Chem. 43, 2971-2974. doi:10.1021/jm0002127

Mangels, N., Awwad, K., Wettenmann, A., Dos Santos, L. R. B., Frömel, T., and Fleming, I. (2016). The soluble epoxide hydrolase determines cholesterol homeostasis by regulating AMPK and SREBP activity. Prostag. Other Lipid Mediat. 125, 30-39. doi:10.1016/j.prostaglandins.2016.05.003

Massafra, V., Pellicciari, R., Gioiello, A., and van Mil, S. W. C. (2018). Progress and challenges of selective Farnesoid X Receptor modulation. Pharmacol. Ther. 191, 162-177. doi:10.1016/j.pharmthera.2018.06.009

McGarry, J. D. (1992). What if Minkowski had been ageusic? an alternative angle on diabetes. Science 258, 766-770. doi:10.1126/science.1439783

Mendez, M., and LaPointe, M. C. (2003). PPAR $\gamma$ inhibition of cyclooxygenase-2, PGE2 synthase, and inducible nitric oxide synthase in cardiac myocytes. Hypertension 42, 844-850. doi:10.1161/01.HYP.0000085332.69777.D1

Merk, D., Gabler, M., Gomez, R. C., Flesch, D., Hanke, T., Kaiser, A., et al. (2014a). Anthranilic acid derivatives as novel ligands for farnesoid X receptor (FXR). Bioorg. Med. Chem. 22, 2447-2460. doi:10.1016/j.bmc.2014.02.053

Merk, D., Lamers, C., Ahmad, K., Carrasco Gomez, R., Schneider, G., Steinhilber, D., et al. (2014b). Extending the structure-activity relationship of anthranilic acid derivatives as farnesoid $\mathrm{X}$ receptor modulators: development of a highly potent partial farnesoid X receptor agonist. J. Med. Chem. 57, 8035-8055. doi:10.1021/jm500937v

Merk, D., Lamers, C., Weber, J., Flesch, D., Gabler, M., Proschak, E., et al. (2015). Anthranilic acid derivatives as nuclear receptor modulators--development of novel PPAR selective and dual PPAR/FXR ligands. Bioorg. Med. Chem. 23, 499-514. doi:10.1016/j.bmc.2014.12.013

Michalik, L., Auwerx, J., Berger, J. P., Chatterjee, V. K., Glass, C. K., Gonzalez, F. J., et al. (2006). International union of pharmacology. LXI. Peroxisome proliferatoractivated receptors. Pharmacol. Rev. 58, 726-741. doi:10.1124/pr.58.4.5

Mihalic, J. T., Chen, X., Fan, P., Chen, X., Fu, Y., Liang, L., et al. (2011). Discovery of a novel series of melanin-concentrating hormone receptor 1 antagonists for the treatment of obesity. Bioorg. Med. Chem. Lett. 21, 7001-7005. doi:10.1016/j. bmcl.2011.09.110

Molinar-Toribio, E., Pérez-Jiménez, J., Ramos-Romero, S., Lluís, L., SánchezMartos, V., Taltavull, N., et al. (2014). Cardiovascular disease-related parameters and oxidative stress in SHROB rats, a model for metabolic syndrome. PLoS One 9, e104637. doi:10.1371/journal.pone.0104637

Moore, D. D. (2012). Nuclear receptors reverse McGarry's vicious cycle to insulin resistance. Cell Metabol. 15, 615-622. doi:10.1016/j.cmet.2012.03.016

Morisseau, C., and Hammock, B. D. (2013). Impact of soluble epoxide hydrolase and epoxyeicosanoids on human health. Annu. Rev. Pharmacol. Toxicol. 53, 37-58. doi:10.1146/annurev-pharmtox-011112-140244

Morisseau, C. (2013). Role of epoxide hydrolases in lipid metabolism. Biochimie 95, 91-95. doi:10.1016/j.biochi.2012.06.011

Morphy, R., and Rankovic, Z. (2005). Designed multiple ligands. an emerging drug discovery paradigm. J. Med. Chem. 48, 6523-6543. doi:10.1021/jm058225d

Morphy, R., and Rankovic, Z. (2006). The physicochemical challenges of designing multiple ligands. J. Med. Chem. 49, 4961-4970. doi:10.1021/jm0603015

Mudaliar, S., Henry, R. R., Sanyal, A. J., Morrow, L., Marschall, H.-U., Kipnes, M., et al. (2013). Efficacy and safety of the farnesoid X receptor agonist obeticholic acid in patients with type 2 diabetes and nonalcoholic fatty liver disease. Gastroenterology 145, 574-582. doi:10.1053/j.gastro.2013.05.042

Naik, P., Murumkar, P., Giridhar, R., and Yadav, M. R. (2010). Angiotensin II receptor type 1 (AT1) selective nonpeptidic antagonists-a perspective. Bioorg. Med. Chem. 18, 8418-8456. doi:10.1016/j.bmc.2010.10.043

Naruse, M., Koike, Y., Kamei, N., Sakamoto, R., Yambe, Y., and Arimitsu, M. (2019). Effects of azilsartan compared with telmisartan on insulin resistance in patients with essential hypertension and type 2 diabetes mellitus: an open-label, randomized clinical trial. PLoS One 14, e0214727. doi:10.1371/journal.pone.0214727

Nelson, M., Bhandari, N., and Wener, J. (2014). Sitagliptin-induced pancreatitis - a longer road than expected. Clin. Case Rep. 2, 149-152. doi:10.1002/ccr3.83
Neuschwander-Tetri, B. A., Loomba, R., Sanyal, A. J., Lavine, J. E., Van Natta, M. L., Abdelmalek, M. F., et al. (2015). Farnesoid X nuclear receptor ligand obeticholic acid for non-cirrhotic, non-alcoholic steatohepatitis (FLINT): a multicentre, randomised, placebo-controlled trial. Lancet 385, 956-965. doi:10. 1016/S0140-6736(14)61933-4

Newman, J. W., Morisseau, C., and Hammock, B. D. (2005). Epoxide hydrolases: their roles and interactions with lipid metabolism. Prog. Lipid Res. 44, 1-51. doi:10.1016/j.plipres.2004.10.001

Noale, M., Veronese, N., Perin, P. C., Pilotto, A., Tiengo, A., Crepaldi, G., et al. (2016). Reply to Letter to the Editor "Polypharmacy in elderly people with diabetes admitted to hospital. Acta Diabetol. 53, 859-860. doi:10.1007/s00592015-0819-8

Nomura, M., Tanase, T., Ide, T., Tsunoda, M., Suzuki, M., Uchiki, H., et al. (2003). Design, synthesis, and evaluation of substituted phenylpropanoic acid derivatives as human peroxisome proliferator activated receptor activators. discovery of potent and human peroxisome proliferator activated receptor alpha subtypeselective activators. J. Med. Chem. 46, 3581-3599. doi:10.1021/jm0205144

Odori, S., Hosoda, K., Tomita, T., Fujikura, J., Kusakabe, T., Kawaguchi, Y., et al. (2013). GPR119 expression in normal human tissues and islet cell tumors: evidence for its islet-gastrointestinal distribution, expression in pancreatic beta and alpha cells, and involvement in islet function. Metabolism 62, 70-78. doi:10. 1016/j.metabol.2012.06.010

Omran, Z. (2017). Obesity: current treatment and future horizons. Mini Rev. Med. Chem. 17, 51-61. doi:10.2174/1389557516666160617100328

Oseini, A. M., and Sanyal, A. J. (2017). Therapies in non-alcoholic steatohepatitis (NASH). Liver Int. 37, 97-103. doi:10.1111/liv.13302

Pacurari, M., Kafoury, R., Tchounwou, P. B., and Ndebele, K. (2014). The ReninAngiotensin-aldosterone system in vascular inflammation and remodeling. Int. J. Inflamm. 2014, 689360. doi:10.1155/2014/689360

Panigrahy, D., Edin, M. L., Lee, C. R., Huang, S., Bielenberg, D. R., Butterfield, C. E., et al. (2012). Epoxyeicosanoids stimulate multiorgan metastasis and tumor dormancy escape in mice. J. Clin. Invest. 122, 178-191. doi:10.1172/JCI58128

Pavlov, T. S., Ilatovskaya, D. V., Levchenko, V., Mattson, D. L., Roman, R. J., and Staruschenko, A. (2011). Effects of cytochrome P-450 metabolites of arachidonic acid on the epithelial sodium channel (ENaC). Am. J. Physiol. Ren. Physiol. 301, F672-F681. doi:10.1152/ajprenal.00597.2010

Pellicciari, R., Fiorucci, S., Camaioni, E., Clerici, C., Costantino, G., Maloney, P. R., et al. (2002). 6alpha-ethyl-chenodeoxycholic acid (6-ECDCA), a potent and selective FXR agonist endowed with anticholestatic activity. J. Med. Chem. 45, 3569-3572. doi:10.1021/jm025529g

Petäjä, E. M., and Yki-Järvinen, H. (2016). Definitions of normal liver fat and the association of insulin sensitivity with acquired and genetic NAFLD-A systematic review. Int. J. Mol. Sci. 17. doi:10.3390/ijms17050633

Pineda Torra, I., Claudel, T., Duval, C., Kosykh, V., Fruchart, J.-C., and Staels, B. (2003). Bile acids induce the expression of the human peroxisome proliferatoractivated receptor alpha gene via activation of the farnesoid X receptor. Mol. Endocrinol. 17, 259-272. doi:10.1210/me.2002-0120

Potenza, M. V., and Mechanick, J. I. (2009). The metabolic syndrome: definition, global impact, and pathophysiology. Nutr. Clin. Pract. 24, 560-577. doi:10. 1177/0884533609342436

Preidis, G. A., Kim, K. H., and Moore, D. D. (2017). Nutrient-sensing nuclear receptors PPARa and FXR control liver energy balance. J. Clin. Invest. 127, 1193-1201. doi:10.1172/JCI88893

Proschak, E., Stark, H., and Merk, D. (2019). Polypharmacology by design: a medicinal chemist's perspective on multitargeting compounds. J. Med. Chem. 62, 420-444. doi:10.1021/acs.jmedchem.8b00760

Przybyla-Zawislak, B. D., Srivastava, P. K., Vazquez-Matias, J., Mohrenweiser, H. W., Maxwell, J. E., Hammock, B. D., et al. (2003). Polymorphisms in human soluble epoxide hydrolase. Mol. Pharmacol. 64, 482-490. doi:10.1124/mol.64.2.482

Rand, A. A., Barnych, B., Morisseau, C., Cajka, T., Lee, K. S. S., Panigrahy, D., et al. (2017). Cyclooxygenase-derived proangiogenic metabolites of epoxyeicosatrienoic acids. Proc. Natl. Acad. Sci. U.S.A. 114, 4370-4375. doi:10.1073/pnas.1616893114

Regulski, M., Regulska, K., Stanisz, B. J., Murias, M., Gieremek, P., Wzgarda, A., et al. (2015). Chemistry and pharmacology of Angiotensin-converting enzyme inhibitors. Curr. Pharmaceut. Des. 21, 1764-1775. doi:10.2174/ 1381612820666141112160013 
Ries, U. J., Mihm, G., Narr, B., Hasselbach, K. M., Wittneben, H., Entzeroth, M., et al. (1993). 6-Substituted benzimidazoles as new nonpeptide angiotensin II receptor antagonists: synthesis, biological activity, and structure-activity relationships. J. Med. Chem. 36, 4040-4051. doi:10.1021/jm00077a007

Ritter, K., Buning, C., Halland, N., Pöverlein, C., and Schwink, L. (2016). G proteincoupled receptor 119 (GPR119) agonists for the treatment of diabetes: recent progress and prevailing challenges. J. Med. Chem. 59, 3579-3592. doi:10.1021/ acs.jmedchem.5b01198

Rivera, C. A. (2008). Risk factors and mechanisms of non-alcoholic steatohepatitis. Pathophysiology 15, 109-114. doi:10.1016/j.pathophys.2008.04.003

Rollason, V., and Vogt, N. (2003). Reduction of polypharmacy in the elderly: a systematic review of the role of the pharmacist. Drugs Aging 20, 817-832. doi:10.2165/00002512-200320110-00003

Rui, L. (2014). Energy metabolism in the liver. Comp. Physiol. 4, 177-197. doi:10. $1002 /$ cphy.c130024

Sargent, B. J., and Moore, N. A. (2009). New central targets for the treatment of obesity. Br. J. Clin. Pharmacol. 68, 852-860. doi:10.1111/j.1365-2125.2009.03550.x

Sattigeri, J. A., Sethi, S., Davis, J. A., Ahmed, S., Rayasam, G. V., Jadhav, B. G., et al. (2017). Approaches towards the development of chimeric DPP4/ACE inhibitors for treating metabolic syndrome. Bioorg. Med. Chem. Lett. 27, 2313-2318. doi:10.1016/j.bmcl.2017.04.036

Savkur, R. S., Bramlett, K. S., Michael, L. F., and Burris, T. P. (2005). Regulation of pyruvate dehydrogenase kinase expression by the farnesoid $\mathrm{X}$ receptor. Biochem. Biophys. Res. Commun. 329, 391-396. doi:10.1016/j.bbrc.2005.01.141

Scheen, A. J. (2015). A review of gliptins for 2014. Expet Opin. Pharmacother. 16, 43-62. doi:10.1517/14656566.2015.978289

Scheen, A. J. (2018). The safety of gliptins : updated data in 2018. Expet Opin. Drug Saf. 17, 387-405. doi:10.1080/14740338.2018.1444027

Schmidt, J., Rotter, M., Weiser, T., Wittmann, S., Weizel, L., Kaiser, A., et al. (2017). A dual modulator of farnesoid $\mathrm{X}$ receptor and soluble epoxide hydrolase to counter nonalcoholic steatohepatitis. J. Med. Chem. 60, 7703-7724. doi:10. 1021/acs.jmedchem.7b00398

Schmieder, R. E. (2005). Mechanisms for the clinical benefits of angiotensin II receptor blocker. Am. J. Hypertens. 18, 720-30. doi:10.1016/j.amjhyper.2004.11.032

Schuck, R. N., Zha, W., Edin, M. L., Gruzdev, A., Vendrov, K. C., Miller, T. M., et al. (2014). The cytochrome P450 epoxygenase pathway regulates the hepatic inflammatory response in fatty liver disease. PLoS One 9, e110162. doi:10. 1371/journal.pone.0110162

Shah, P., and Mudaliar, S. (2010). Pioglitazone: side effect and safety profile. Expet Opin. Drug Saf. 9, 347-354. doi:10.1517/14740331003623218

Shaw, J. E., Sicree, R. A., and Zimmet, P. Z. (2010). Global estimates of the prevalence of diabetes for 2010 and 2030. Diabetes Res. Clin. Pract. 87, 4-14. doi:10.1016/j.diabres.2009.10.007

Shen, H. C., and Hammock, B. D. (2012). Discovery of inhibitors of soluble epoxide hydrolase: a target with multiple potential therapeutic indications. J. Med. Chem. 55, 1789-1808. doi:10.1021/jm201468j

Sime, M., Allan, A. C., Chapman, P., Fieldhouse, C., Giblin, G. M. P., Healy, M. P., et al. (2011). Discovery of GSK1997132B a novel centrally penetrant benzimidazole PPAR $\gamma$ partial agonist. Bioorg. Med. Chem. Lett. 21, 5568-5572. doi:10.1016/j.bmcl.2011.06.088

Spector, A. A. (2009). Arachidonic acid cytochrome P450 epoxygenase pathway. J. Lipid Res. 50 (Suppl. 1), S52-S56. doi:10.1194/jlr.R800038-JLR200

Spector, A. A., and Norris, A. W. (2007). Action of epoxyeicosatrienoic acids on cellular function. Am. J. Physiol. Cell Physiol. 292, C996-C1012. doi:10.1152/ ajpcell.00402.2006

Stafylas, P. C., Sarafidis, P. A., and Lasaridis, A. N. (2009). The controversial effects of thiazolidinediones on cardiovascular morbidity and mortality. Int. J. Cardiol. 131, 298-304. doi:10.1016/j.ijcard.2008.06.005

Stavniichuk, A., Hye Khan, M. A., Yeboah, M. M., Chesnik, M. A., Jankiewicz, W. K., Hartmann, M., et al. (2020). Dual soluble epoxide hydrolase inhibitor/ PPAR- $\gamma$ agonist attenuates renal fibrosis. Prostag. Other Lipid Mediat. 150, 106472. doi:10.1016/j.prostaglandins.2020.106472

Sumida, Y., and Yoneda, M. (2018). Current and future pharmacological therapies for NAFLD/NASH. J. Gastroenterol. 53, 362-376. doi:10.1007/s00535-017$1415-1$

Takahashi, Y., Soejima, Y., and Fukusato, T. (2012). Animal models of nonalcoholic fatty liver disease/nonalcoholic steatohepatitis. World J. Gastroenterol. 18, 2300-2308. doi:10.3748/wjg.v18.i19.2300
Takekawa, S., Asami, A., Ishihara, Y., Terauchi, J., Kato, K., Shimomura, Y., et al. (2002). T-226296: a novel, orally active and selective melanin-concentrating hormone receptor antagonist. Eur. J. Pharmacol. 438, 129-135. doi:10.1016/ s0014-2999(02)01314-6

Tanaka, H., Kamita, S. G., Wolf, N. M., Harris, T. R., Wu, Z., Morisseau, C., et al. (2008). Transcriptional regulation of the human soluble epoxide hydrolase gene EPHX2. Biochim. Biophys. Acta. 1779, 17-27. doi:10.1016/j.bbagrm.2007. 11.005

Timmermans, P. B. (1999). Pharmacological properties of angiotensin II receptor antagonists. Can. J. Cardiol. 15, 26F-8F.

Tomlinson, B., Hu, M., Zhang, Y., Chan, P., and Liu, Z.-M. (2016). Investigational glucagon-like peptide-1 agonists for the treatment of obesity. Expet Opin. Invest. Drugs 25, 1167-1179. doi:10.1080/13543784.2016.1221925

Tontonoz, P., and Spiegelman, B. M. (2008). Fat and beyond: the diverse biology of PPARgamma. Annu. Rev. Biochem. 77, 289-312. doi:10.1146/annurev. biochem.77.061307.091829

Toulis, K. A., Nirantharakumar, K., Pourzitaki, C., Barnett, A. H., and Tahrani, A. A. (2020). Glucokinase activators for type 2 diabetes: challenges and future developments. Drugs 80 (5), 467-475. doi:10.1007/s40265-020-01278-z

Tully, D. C., Rucker, P. V., Chianelli, D., Williams, J., Vidal, A., Alper, P. B., et al. (2017). Discovery of tropifexor (LJN452), a highly potent non-bile acid FXR agonist for the treatment of cholestatic liver diseases and nonalcoholic steatohepatitis (NASH). J. Med. Chem. 60, 9960-9973. doi:10.1021/acs.jmedchem.7b00907

Vitale, C., Mercuro, G., Castiglioni, C., Cornoldi, A., Tulli, A., Fini, M., et al. (2005). Metabolic effect of telmisartan and losartan in hypertensive patients with metabolic syndrome. Cardiovasc. Diabetol. 4, 6. doi:10.1186/1475-2840-4-6

Wang, Y., Landheer, S., van Gilst, W. H., van Amerongen, A., Hammes, H.-P., Henning, R. H., et al. (2012). Attenuation of renovascular damage in Zucker diabetic fatty rat by NWT-03, an egg protein hydrolysate with ACE- and DPP4inhibitory activity. PLoS One 7, e46781. doi:10.1371/journal.pone.0046781

Wang, Y., Qiao, S., Han, D.-W., Rong, X.-R., Wang, Y.-X., Xue, J.-J., et al. (2018). Telmisartan improves insulin resistance: a meta-analysis. Am. J. Ther. 25, e642-e651. doi:10.1097/MJT.0000000000000733

Watanabe, M., Houten, S. M., Wang, L., Moschetta, A., Mangelsdorf, D. J., Heyman, R. A., et al. (2004). Bile acids lower triglyceride levels via a pathway involving FXR, SHP, and SREBP-1c. J. Clin. Invest. 113, 1408-1418. doi:10.1172/JCI21025

Willson, T. M., Brown, P. J., Sternbach, D. D., and Henke, B. R. (2000). The PPARs: from orphan receptors to drug discovery. J. Med. Chem. 43, 527-550. doi:10. $1021 / \mathrm{jm} 990554 \mathrm{~g}$

Xu, D., Davis, B. B., Wang, Z., Zhao, S., Wasti, B., Liu, Z., et al. (2013). A potent soluble epoxide hydrolase inhibitor, t-AUCB, acts through $\operatorname{PPAR} \gamma$ to modulate the function of endothelial progenitor cells from patients with acute myocardial infarction. Int. J. Cardiol. 167, 1298-1304. doi:10.1016/j. ijcard.2012.03.167

Yang, J. W., Kim, H. S., Choi, Y.-W., Kim, Y.-M., and Kang, K. W. (2018). Therapeutic application of GPR119 ligands in metabolic disorders. Diabetes Obes. Metabol. 20, 257-269. doi:10.1111/dom.13062

Zhang, G., Panigrahy, D., Hwang, S. H., Yang, J., Mahakian, L. M., Wettersten, H. I., et al. (2014). Dual inhibition of cyclooxygenase-2 and soluble epoxide hydrolase synergistically suppresses primary tumor growth and metastasis. Proc. Natl. Acad. Sci. U.S.A. 111, 11127-11132. doi:10.1073/pnas. 1410432111

Conflict of Interest: JI and EP have multiple patent applications that covers the composition of matter for dual PPAR $\gamma / \mathrm{sEH}$ and FXR/sEH ligands.

The remaining author declares that the research was conducted in the absence of any commercial or financial relationships that could be construed as a potential conflict of interest.

Copyright (c) 2021 Lillich, Imig and Proschak. This is an open-access article distributed under the terms of the Creative Commons Attribution License (CC $B Y)$. The use, distribution or reproduction in other forums is permitted, provided the original author(s) and the copyright owner(s) are credited and that the original publication in this journal is cited, in accordance with accepted academic practice. No use, distribution or reproduction is permitted which does not comply with these terms. 


\section{GLOSSARY}

AA arachidonic acid

ACE angiotensin converting enzyme

AcH acetylcholine

AMP adenosine monophosphate

Ang I/ II angiotensin I/ II

APP aminopeptidase P

APN aminopeptidase N

AT1 angiotensin II receptor subtype 1

BA bile acid

cAMP cyclic adenosine monophosphate

CB1 cannabinoid type 1

CDCA Chenodeoxycholic acid

CHF congestive heart failure

COX cyclooxygenase

CYP cytochrome P450

DASH dipeptidyl peptidase-IV activity and/or structure homologues

DHETs dihydroxyepoxyeicosatrienoic acids

DML designed multitarget ligand

DPP4 dipeptidyl peptidase-4

EDR endothelium dependent relaxation

EETs epoxyeicosatrienoic acids

ENaCs epithelial sodium channels

EPC epithelial progenitor cells

FGS focal glomerulosclerosis

FLINT Farnesoid X nuclear receptor ligand obeticholic acid for noncirrhotic, non-alcoholic steatohepatitis

FXR farnesoid X receptor

GK Glucokinase

GLP-1 glucagon-like peptide-1

$\mathbf{G P}(\mathbf{C}) \mathbf{R}$ G-protein coupled receptor

HbAlc hemoglobin Alc

hERG human ether-a-go-go-related gene

HETE hydroxyeicosatrienoic acid

HIF-1a Hypoxia-inducible factor 1-alpha
HSCs human hepatic stellate cells

IL-6 interleukin-6

HDL high-density lipoprotein

HMG-CoA 3 hydroxy-3-methyl-glutaryl-coenzyme A

LDL low-density lipoprotein

LH lateral hypothalamus

MCH melanin-concentrating hormone

MCH-1R melanin concentrating hormone receptor 1

MCP-1 monocyte chemoattractant protein-1

MetS Metabolic syndrome

NAFLD non-alcoholic fatty liver disease

NASH non-alcoholic steatohepatitis

NEP neutral endopeptidase

OCA obeticholic acid

OEA oleoylethanolamides

PPARs proliferator-activated receptors

PPCE post-proline cleaving enzyme

RA(A)S renin-angiotensin-aldosterone system

RXR retionoid-X-receptor

SAR structure-activity relationship

sDDP4 soluble dipeptidyl peptidase-4

sEH soluble epoxide hydrolase

sEH-I soluble epoxide hydrolase-inhibitor

SGLT-2 sodium-glucose cotransporter-2

SHR spontaneously hypertensive rats

SHROB rat spontaneously hypertensive obese rat

T2DM type 2 diabetes mellitus

TGF- $\boldsymbol{\beta}$ transforming growth factor beta

TNF- $\boldsymbol{\alpha}$ tumor necrosis factor- $\boldsymbol{\alpha}$

TZD thiazolidinedione

UUO unilateral ureteral obstruction

VEGF vascular endothelial growth factor

ZDF ratzucker diabetic fatty rat

ZSF1 ratzucker fatty/spontaneously hypertensive heart failure F1 hybrid rat 